\title{
An Overview on Structural Health Monitoring: From the Current State-of-the-Art to New Bio-inspired Sensing Paradigms
}

\author{
Maria-Giovanna Masciotta ${ }^{a *}$, Alberto Barontini ${ }^{a}$, Luís F. Ramos ${ }^{a}$, Paulo Amado-Mendes ${ }^{b}$, Paulo \\ B. Lourenço ${ }^{a}$
}

${ }^{a}$ ISISE, University of Minho, Department of Civil Engineering, Campus de Azurém, 4800-058 Guimarães, Portugal

${ }^{b}$ ISISE, University of Coimbra, Department of Civil Engineering, Rua Luís Reis Santos - Pólo II da

Universidade, 3030 - 788 Coimbra, Portugal

Maria-Giovanna Masciotta obtained her dual-degree $\mathrm{PhD}$ in 2015 within a joint programme between the University of Minho (Portugal) and the University of "G. d'Annunzio" of Chieti-Pescara (Italy), being therefore awarded the mention of "Doctor Europeaus". Since 2012, she has been carrying out her research activity at the Institute for Sustainability and Innovation in Structural Engineering (ISISE), which is the largest research unit in Portugal in the field of Structural Engineering.

Her research interests are related to the engaging fields of modal testing, structural health monitoring and damage identification of heritage structures, being author of several publications on these subjects, but also include bio-inspired sensing paradigms and advanced structural analysis of masonry constructions.

Alberto Barontini, graduated in Civil Engineering by University of Florence, in 2015, is currently conducting his $\mathrm{PhD}$ programme on bio-inspired Structural Health Monitoring systems at University of Minho, in collaboration with University of Coimbra.

His research domains include the study of bio-inspired optimization and learning algorithms applied to identification (detection, localization and quantification) of damage and safety assessment.

His research interests also include in-situ non-destructive testing, advanced structural analysis, dynamics of structures and earthquake engineering.

Luís F. Ramos, graduated in Civil Engineer by University of Minho in 1999, made his doctorate thesis in 2007, also in University of Minho, about Damage Identification on Masonry Structures based on Vibration Signatures.

His current research interests include non-destructive tests for damage detection, structural health monitoring of ancient constructions, dynamic tests, finite element analysis, non-linear analysis of masonry constructions, and earth constructions, being author of several publications, in both conferences and in specialized journals, on those topics.

He has been involved in several specialized consultancy projects in monuments and in several research projects.

Paulo Amado-Mendes, graduated in Civil Engineering at the University of Coimbra (Portugal) in 2001, completed his PhD in Civil Engineering, specialization Construction Sciences, in 2010, also at the University of Coimbra.

His scientific areas of research comprise: civil engineering and applied physics and mechanics; wave propagation in elastic and acoustic media; fluvial and maritime hydraulics and sediment transport and

"Corresponding author.

E-mail: mg.masciotta@gmail.com Tel: +351917099832 Fax: +351 253510217 
dynamics; numerical modelling with boundary/traction boundary element method and other numerical meshless methods; and non-destructive evaluation techniques.

Assistant Professor at the University of Coimbra, he has supervised 21 concluded MSc theses, and he is currently supervising $4 \mathrm{PhD}$ students and $5 \mathrm{MSc}$ students.

He has participated in several research projects, in the area of Construction Sciences, being co-author of several publications in both international conferences and scientific journals.

Paulo B. Lourenço, Civil Engineer from the University of Porto in 1990, and $\mathrm{PhD}$ in 1996 from the Technical University of Delft, The Netherlands, on computational methods in masonry structures.

Full Professor and Head of the Structures Group at the University of Minho.

His field of research covers non-destructive testing, advanced numerical and experimental techniques, innovative reinforcement techniques and seismic engineering with a focus on masonry and wood. He worked as a consultant in more than 75 monuments in Portugal and abroad.

He has supervised more than 40 doctoral theses and 50 master's theses. He is Editor of the International Journal of Architectural Heritage, Coordinator of the European Masters in Structural Analysis of Monuments and Historic Buildings (www.msc-sahc.org) and Coordinator of the revision of Eurocode 6 (Part 1).

\begin{abstract}
In the last decades, the field of structural health monitoring (SHM) has grown exponentially. Yet, several technical constraints persist, which are preventing full realization of its potential. To upgrade current state-of-the-art technologies, researchers have started to look at nature's creations giving rise to a new field called 'biomimetics', which operates across the border between living and non-living systems. The highly optimised and time-tested performance of biological assemblies keeps on inspiring the development of bio-inspired artificial counterparts that can potentially outperform conventional systems. After a critical appraisal on the current status of SHM, this paper presents a review of selected works related to neural, cochlea and immune-inspired algorithms implemented in the field of SHM, including a brief survey of the advancements of bio-inspired sensor technology for the purpose of SHM. In parallel to this engineering progress, a more in-depth understanding of the most suitable biological patterns to be transferred into multimodal SHM systems is fundamental to foster new scientific breakthroughs. Hence, grounded in the dissection of three selected human biological systems, a framework for new bio-inspired sensing paradigms aimed at guiding the identification of tailored attributes to transplant from nature to SHM is outlined.
\end{abstract}

\title{
Keywords
}


Structural health monitoring (SHM), nature-inspired sensing paradigms, bio-inspired algorithms, bioinspired SHM sensors, biomimicry.

\section{Introduction}

Built environment is continuously exposed to the risk of structural damage whether due to ageing effects, excessive loads, accidents or extreme events. If not timely detected, damage will inevitably impair the structural performance, jeopardizing the integrity of the system. This is a major concern in case of strategic civil structures and infrastructures, such as bridges, dams and buildings, among others, where the need to meet life-safety standards is emphasized by the critical role these systems play within the economy of our countries. Moreover, the costs associated with catastrophic collapses are often unsustainable. The timely identification of structural damage is therefore crucial to avoid unexpected failures, ensure structural performance and enhance public safety. Millions of euros are currently invested in conventional maintenance routines based on time-consuming and rather subjective visual inspection procedures which, in most cases, result insufficient for safety evaluation, as the majority of structural defects lie (unseen) beneath the surface of the structure (Moore et al., 2001). To track and keep under control the structural behaviour, including the onset and evolution of hidden damage mechanisms, structural health monitoring (SHM) systems are the best tools available up to date. Such systems can provide valuable and nearly real-time information for assessing integrity, durability and reliability of structures, allowing to quantify changes in the structures' inherent characteristics and to early detect structural faults even if not visible to human eyes. Yet, recent disasters have shown that there is a mismatch between budget spent on SHM systems and improvement of life-safety standards. While SHM systems can potentially offer the possibility to obtain accurate condition screenings of the structural health, the problems and technical limitations of current sensing platforms still continue to make the damage identification task very challenging. Damage, by its nature, is a highly localized phenomenon, thus the careful selection and deployment of sensors are critical for its detection. To obtain reliable and high quality structural information, it is important to monitor the structural behavior at finegrained level, ensuring a sufficiently large number of sensors. Unfortunately, in what concerns civil 
structures, budget limitations often result in the installation of sparsely distributed monitoring systems, poorly scaled with structural damage, mainly because of the high costs associated with traditional tethered systems (Loh et al., 2015). Numerous wireless technologies have emerged over the past decades aiming at providing relatively inexpensive sensor platforms with densely distributed data acquisition nodes for autonomous SHM and damage detection. However, although these considerable advancements, modern SHM systems still present several limitations which are preventing full realization of their potential. Among the main problems are: inappropriate instrumentation and sensor overload, reliable network topology, data compression and transmission, data mining, energy consumption and storage cost, environmental and noise effects (Brownjohn, 2007).

Intelligent sensors strategically deployed within a flexible hierarchical network topology are required to ensure a clever multi-level screening of structures while reducing operation and maintenance costs. Similar optimal conditions have already been accomplished in biological systems. For instance, analogies can be found with the human skin which is known to have a network of more than 600.000 sensors distributed over an area of less than two square meters. Such a dense network of sensors can detect and process different physical stimuli of pressure, temperature and pain, thereby being of vital importance for the preservation of the human body. Another example is the central nervous system with its complex inter-connected architectures of neurons, which are able to process vast amount of information at very fast rates with minimal energy costs, and whose redundancy guarantees failure tolerance of single neural cells without compromising the efficiency of the overall system. Current research activities in the field of SHM are already addressing their attention to the emulation of nature's time-tested patterns to develop bio-inspired artificial counterparts that can potentially outperform conventional systems. Cutting-edge topics encompass bio-inspired algorithms for best sensor placement and damage detection, intelligent sensor networks with sleep/wake options for enhancing energy efficiency, skin-like and mobile robotic sensors for optimum network coverage. However, a more indepth understanding of biological systems and their assemblies is necessary to effectively drive new scientific and technological breakthroughs in bio-inspired SHM.

In light of the above considerations, the main scope of this paper is to present an overview on the current status of structural health monitoring, with focus on selected examples of bio-inspired algorithms 
applied in the field of SHM, namely neural, cochlea and immune -inspired algorithms. This paper is not meant to be an exhaustive literature review on the topic. Only a selection of published works is sampled and presented to showcase different ideas and the breadth of research. The remainder of this document is organised as follows. Section 2 gives a summary of SHM developments over time and provides a critical analysis of current health monitoring techniques. Deficiencies and technical limitations of modern SHM architecture are addressed in Section 3, pointing out possible improvement solutions. After a concise introduction on biomimicry concepts and bio-inspired systems in different fields and applications, Section 4 reviews selected works on bio-inspired algorithms implemented in the field of SHM. Section 5 proposes a dialectic framework to foster a more in-depth understanding of the most suitable biological patterns that can be transferred into engineered SHM systems. Finally, Section 6 reports the main conclusions of the work, highlighting future trends and needs.

\section{Traditional vs modern approaches in SHM}

\subsection{Overview and motivation for SHM technology development}

In general terms, Structural Health Monitoring (SHM) can be defined as the systematic online process of observing, tracking and sampling data over a period of time, in order to assess the fitness for purpose of structural systems under inevitable ageing and damage accumulation resulting from operational and environmental conditions. Although the first forms of structural monitoring, based on visual inspections and simple offline data collection methods, date back to long time ago, the term SHM was formally 'standardized' only in the last decades, when the advances in software and hardware technologies led to the advent of automated data acquisition and processing systems (Brownjohn, 2007). At the same time, the need for a holistic approach to SHM started to emerge (Fanelli, 1992). The most significant developments in SHM originated from major construction projects, such as large dams (Comerford et al., 1992; Darbre and Proulx, 2002; Severn et al., 1981), large-scale bridges (Bampton et al., 1986; Barr et al., 1987; Leitch et al., 1987; Cheung et al., 1997; Maeck et al., 2001; Ko and Ni, 2005), offshore platforms (Coppolino and Rubin, 1980; Kenley and Dodds, 1980; Shahrivar and Bouwkamp, 1984; Brederode et al., 1986), nuclear installations (Smith, 1996), tunnels and excavations (Okundi et al., 2003; Tan and Chua, 2003). The primary scope was to gain a better insight into the structural behaviour 
of such systems during construction activities, normal operation and extreme events, such as earthquakes, strong winds and floods, by tracking specific parameters suitable for the extraction of information regarding the structural response and for the identification of possible anomalous changes. In what concerns buildings and civil infrastructures, motivation for SHM initially resulted from the need to timely evaluate the structural safety against significant seismic events (Brownjohn, 2007; Rainieri et at., 2010) and to assess the structural response to environmental and operational conditions, including temperature effects, traffic loadings and wind speed (Magalhães et al., 2012; Cross et al., 2013; Comanducci et al., 2015). Still, the growing interest in the preservation and maintenance of strategic civil structures considerably fuelled the development of systematic approaches for SHM (Tan and Chua, 2003; Farrar and Lieven, 2007; Farrar and Worden, 2007; Carden and Brownjohn, 2008; Rainieri et al., 2011; Langone et al., 2017; Worden and Cross, 2018). Response data generated by structural monitoring systems are currently used to: (i) provide real-time baseline information on the system's health, (ii) set performance standards, (iii) detect anomalies and deviations of the structural response from the ordinary behaviour, (iv) validate design models, (v) monitor, control and evaluate the effectiveness of retrofit interventions and repair activities. Vibration data from SHM systems also play a leading role when dealing with built architectural heritage, where the need to respect the historical value of the constructions often limits the range of applicable techniques for the system's characterization. In this regard, hSHM (heritage-SHM) practices are being employed with a twofold aim, viz. as a diagnosis tool and as a control tool, holding an active role throughout the entire preservation process of historic structures (Ramos et al., 2010; Ramos et al., 2013; Saisi et al., 2016; Ubertini et al., 2016; Masciotta et al, 2016; Masciotta et al., 2017). Recently, great endeavours have been made in the field of vibration-based damage identification, but the possibility to efficiently embed damage detection algorithms within monitoring systems in order to automate the task of assessing structural health is still under development (Lynch, 2007; Avci et al., 2018). Furthermore, the inherent limitations of actual monitoring technologies have induced the civil engineering community to explore new SHM sensing paradigms so as to advance the current state-of-practice for optimal data collection and intelligent data interpretation. In particular, attention is being devoted to the field of biomimicry, as it will be discussed in the next sections. 


\subsection{Classification of current SHM techniques}

The field of SHM is rather wide-ranging and embraces different techniques which can be classified according to various criteria. In general terms, SHM techniques can be categorized in global and local. The former group includes online vibration-based monitoring techniques that are suitable for investigations at the system-level since they allow to obtain information about the overall response of the structure. The latter group consists of offline inspection methods and investigations at the component-level which are mostly beneficial when the target areas are known in advance.

Depending on the type and configuration of sensing and data acquisition systems, SHM techniques can be also classified in traditional (or standard) and modern (or smart). Traditional approaches rely on tethered-based sensing systems which exploit coaxial cables to communicate the response measurements to a central data repository (figure 1a). A certain number of sensors (e.g. accelerometers, displacement transducers, inclinometers, strain gauges or actuators) are deployed at strategic locations throughout the structure, but they are wired back to a single centralized DAQ system where data are stored and processed. Among the key problems intrinsic to the use of cables for SHM purposes are the high cost per sensing node channel, the low flexibility and the significant amount of time and labor needed to install and maintain dense sets of sensors. While extremely reliable in communication, the large number of accompanying wires, fibre optic cables, or other physical transmission media may be prohibitive, particularly for large-scale structures such as long-span bridges or tall buildings (Spencer et al., 2004). Moreover, wires are susceptible to tearing, rodent nibbling and measurement corruption through signal noise, thus they need to be isolated from the harsh environment, causing a further increase in the cost and time of installation (Lynch et al., 2000). This is why tethered monitoring systems typically lack a high spatial density of sensors, resulting in sparsely distributed and poorly scaled networks (Loh et al., 2015). Low sensor densities provide insight into the low-order modal properties of the structure, but for damage detection purposes there is a need for greater monitoring fidelity that is only achievable by highly increasing the number of measurement points (Lynch et al., 2000). The limitations and bottlenecks of traditional structural monitoring technologies have prompted structural 
engineering researchers to look over alternative and more modern approaches for performing many of the tasks associated with the health monitoring of civil structures (Lynch, 2007). Most of these approaches are based on the use of sensing units which embody wireless communications and mobile computing elements so as to deliver a relatively inexpensive sensor platform with distributed and autonomous data acquisition nodes not physically linked (figure 1b). Beyond the hardware architecture, each wireless sensor is provided with a computational core, namely an on-board software, responsible for data collection, self-interrogation of measurement data and wireless communication within the sensor network. Thanks to the rapid advances in sensors and the declining cost of computing and communication technologies, various wireless monitoring systems have been designed and tested across a number of different applications. Such systems have the potential to serve as low-cost, highly-flexible and highly-efficient substitutes for traditional tethered monitoring systems as they feature a cheaper and quicker installation as well as superior performance (Lynch and Loh, 2006). Still, despite the benefits, several challenges mainly associated with wireless telemetry must be tackled, e.g. power consumption of batteries, time synchronisation of sensors, long-range communication, lossless data compression and transmission (Ling and Tian, 2010; Jang et al., 2012; Alonso et al., 2018). Setting the goal to take up one challenge or the other, different network topologies for wireless sensor networks (figure 2) have already been proposed both at academic and industrial levels (Lynch and Loh, 2006), but research is still ongoing (Jayawardhana et al., 2017; Abdaoui et al., 2017). An extensive review about the prototype wireless sensing units and the commercial wireless sensor platforms developed so far is not pursued in this study. Several papers fully treating this subject are already available in literature, e.g. Lynch et al., (2000), Farrar et al. (2003), Spencer et al. (2004), Lynch and Loh, (2006), Lynch (2007), just to name a few.

Depending on the capability of the sensors to act both as transmitters and receptors, SHM techniques can be ultimately distinguished in passive and active. Passive systems employ conventional sensors that slavishly record the structural response, whereas active systems involve the use of actuators, i.e. active sensors that are able to excite the system in which they are installed and simultaneously record its response. Examples of passive schemes are acoustic emission and strain/load monitoring, which have been demonstrated with some success (Verstrynge et al., 2018; Behnia et al., 2014; Chiu et al., 2000). 
Among active schemes, guided-wave SHM emerged as a very prominent option (Raghavan and Cesnik, 2007, Yu et al., 2008). In this regard, embedded or surface-bonded wafer piezoelectric sensors are widely used due to their peculiarity to operate by coupling electrical and mechanical energy fields. As the piezoelectric material is electrically activated, strain is induced in the active sensor, and interaction forces and moments appear at the interface between the sensor and the structure. Conversely, when an elastic wave travels through the structure, the active sensor gets activated through the strain/displacement compatibility condition and the induced mechanical strain generates an electric field that is captured as voltage at the actuator terminals (Giurgiutiu, 2014). To take advantage of active sensors in smart health monitoring systems, wireless sensing units with actuation interfaces were conceived in the last decades (Lynch, 2007; Raghavan and Cesnik, 2007). Although promising, such a technology resulted well-suited only for component-level health monitoring and local-based damage detection. To broaden the range of application of active sensing units for SHM purposes, the shortcomings associated with wireless telemetry must be overcome first.

\section{Problems and limitations of modern SHM architecture}

The benefits that structural health monitoring strategies - if properly implemented - might bring into the civil engineering sector in a long-term perspective are countless. The success of these powerful tools in assisting facility managers to maintain their structures safely over time will depend on the ability of the engineering community to address all key problems and technical limitations that are still preventing full realization of SHM potential. Among the wide number of instances, at the top of the pyramid are the over-instrumentation and the consequent data inundation due to inappropriate sensors selection and location. These aspects require the development of reliable algorithms for optimal sensors placement so as to ensure intelligent test planning and to avoid data overload. Another important issue to master concerns the data transmission within the wireless monitoring system. Due to limited communication bandwidth, radio interference and path loss, data acquisition may result inaccurate and incomplete. To enhance the reliability of the wireless communication channel, spread spectrum wireless signals are preferred since narrow-band wireless transmission modulates all data upon a single carrier frequency (Lynch and Loh, 2006). By effectively spreading the signal energy over a broad spectrum, the 
probability of interference on the band may be greatly reduced (Bensky, 2004). Thus, methods for modulating data in a spread spectrum fashion should be implemented in the wireless sensors network (WSN). It is also stressed that wireless sensing units have a limited capacity and lossless data compression techniques must be applied for the purpose of reducing the flow of sensor information as well as energy consumption and storage cost. Novel compressive sensing (CS) techniques able to accurately reconstruct signals with much less number of acquired samples than that defined by Nyquist's theorem have also been investigated (Bao et al., 2011; Bao et al., 2013; Mascarenas et al., 2013; Jayawardhana et al., 2017). Nevertheless, further research and developments to streamline CS for WSNbased SHM are needed. Power supplies of wireless sensors are finite, and the replacement of batteries may result quite difficult in locations that are not easily accessible, therefore preserving energy and storage through data reduction without losing the confidence of accurate decision-making is of utmost importance. Aiming at increasing the life expectancy of the battery packs and so the operational life of the entire monitoring system, a capable computational core should be embedded in each wireless sensing unit. The power demand of the wireless transceiver is proportional to the wavelength of the radio band, thus WSNs hopping data across a number of short-range radios result much more energy efficient than those using a single radio able to transmit over long ranges (Zhao and Guibas, 2004). Alternatively, wireless cluster nodes provided with both short-range and long-range radios can be employed. Clustering approaches can also help improve the scalability of the system, reducing network traffic and making new cluster additions independent from existing ones (Chen et al., 2011). A flexible network management software combining sleep/wake cycles with threshold detection is also recommended to trade off functionality and power consumption. One step forward in this direction has been moved by Ling and Tian (2010) who developed a distributed algorithm for sparse signal recovery in compressive sleeping wireless sensor networks.

Although all afore-mentioned aspects entail an a priori hierarchical planning of the wireless network topology, it is worth noting that improving the WSN architecture before its implementation will ultimately upgrade the SHM system's performance and lead to a clever multi-level screening reducing both operation and maintenance costs, without compromising the accuracy of the outcome. Eventually, some extra effort needs to be made to improve the time synchronization between wireless sensing units 
in order to align data streams at different locations according to a common temporal metric. Indeed, it has been shown that errors due to time shifts between the incoming raw data from each sensor node may adversely impact the mode shape identification and damage detection/localization of the structure under analysis (Abdaoui et al., 2017). Last but not the least is the issue of the influence of ambient factors and background noise on the vibration response of full-scale structures in operation conditions. It is well-known that environmental effects can mask changes due to damage occurrence, thus it is extremely important to distinguish whether variations in the structural response are caused by exogenous factors, such as temperature, humidity, wind, etc., rather than endogenous factors linked to structural damage. The establishment of confidence intervals and appropriate threshold levels may help detect anomalies and deviations from the standard behaviour of the structure. A successful WSN architecture should provide for sensing units with computing procedures capable to spot and filter out environmental and operational variations, and to autonomously execute the embedded damage detection algorithm in real or near real time.

The above considerations highlight that, although successfully used over the past decades in a wide range of applications, WSN-based monitoring systems still do not meet the stringent requirements of Quality of Service (QoS) for the scope of SHM of civil infrastructures (Chen et al., 2011; Alonso et al., 2018). In order to develop reliable SHM systems, architectural and networking issues cannot be addressed in isolation. A cross-layer or holistic approach distinct from previous SHM strategies is needed, and tailored technologies must be conceived.

\section{Bio-inspired engineering}

To overcome grand engineering challenges such as the ones discussed in the previous section, engineers have recently turned to biology for sources of inspiration, giving rise to a new field called bio-inspired engineering. The past two decades have seen a rapid increase in the amount of research related to bioinspired systems as quantified by the significant escalation in the number of papers published on this subject (figure 3). Although growing rapidly both as an academic and as an applied discipline, biomimetics still lacks an analytical framework (Hesselberg, 2007). This section is conceived as an attempt to give a brief overview of this field in order to path the way for the subsequent definition of a 
dialectic framework for new bio-inspired sensing paradigms in the context of structural health monitoring. Due to space limitations, some relevant material will be inevitably left out of consideration, but the intent of the authors is to keep the focus on the sources of bio-inspiration and paradigms that have already found actuation in SHM, so as to easily identify the aspects upon which further research must be addressed in the future for the advancement of SHM.

\subsection{Introduction of biomimicry concepts}

Biomimetics or biomimicry is an interdisciplinary field that identifies potential and useful processes and mechanisms in biological systems and living organisms and imitates them in order to solve complex human problems. Etymologically, the term biomimetics comes from the Greek words bios, meaning life, and mimesis, meaning imitation. The name was coined in the 1950s by the polymath Otto Schmitt (Harkness, 2002), whose doctoral research focused on the development of a physical device that explicitly mimicked the electrical action of a nerve. Few years later, Jack E. Steele of the US Air Force coined the word bionics to indicate the science of systems which have some functions copied from nature (Vincent et al., 2006). According to the definition of the Biomimicry Institute in Missoula (Montana, USA), biomimicry is an approach to innovation that seeks sustainable solutions to human challenges by emulating nature's time-tested patterns and strategies (http://biomimicry.org). The core idea of biomimetics is that Nature has already engineered high-performance, elegant and sustainable systems which have benefited from millions of years of evolution and optimization, and whose capabilities far surpass many of the current available technologies. Hence, biology is regarded as a source of inspiration to give rise to innovative and efficient nature-inspired technologies at macro- and nano-scales in many different fields and applications.

\subsection{Bio-inspired systems in different fields and applications}

Even though biomimetics is a relatively young field, the mankind has been taking hints from biology for centuries. One of the early although unsuccessful attempt of biomimicry dates to the $15^{\text {th }}$ century, when Leonardo Da Vinci tried to build a "flying machine" based on the observation and study of both 
anatomy and flying mechanisms of winged animals. In the last century, with the technology progress and the unification of life and natural sciences with engineering and physical sciences, biomimetics has spurred interest across numerous disciplines and bio-inspired concepts have increasingly been integrated into several areas. Nowadays, the term biomimetics is used in all contexts that involve the transfer of skills or information from biology to applied science (Hesselberg, 2007). The most famous example of biomimicry is the hook-and-loop fastener, also known as Velcro (Velcro, 1955), which was conceived in the late 1940s by the Swiss engineer George de Mestral, after examining under a microscope the burs stuck to his clothes and his dog's fur after returning from a hunting trip. Another example showing the potential of the biomimetical approach is the 'lotus effect' discovered by the botanist Wilhelm Barthlott during a systematic scanning electron microscopy study of the leaf surface of some 10.000 plant species (Barthlott and Neinhuis, 1997). The self-cleaning and water-repellent properties exhibited by the microscopically rough surface of the lotus leaf have inspired a new generation of super-hydrophobic materials. Interesting examples of biomimicry include the exploration of the micro architecture of seashells and nacres to produce lightweight, tough and shatterproof ceramics (Clegg et al., 1990) or the examination of the hierarchical nanostructure of bones for the synthesis of optimal composite materials (Gao, 2006). The replication of the ribbed texture of the shark skin has been used to reduce drag in hulls of sailing boats, military aircrafts (Bechert et al., 2000) and wholebody swimsuits. Functional materials with artificial fibres that mimic the structural features and the directional water-collecting ability of spider's silk have been designed as well (Zheng et al., 2010). This is only a short list within the realm of bio-inspired materials. Many other examples can be found in literature.

Another area that in recent years has turned some attention to the advantages of the biomimetic approach is the area of robotics, which is indeed a natural fit for bio-inspired engineering. A few examples are: the wall-climbing robot developed after studying both tread and adhesive foot surface of geckos (Menon and Setti, 2006); the bio-inspired robot created after the locomotion of the lobster for the easy traverse of underwater terrains (Ayers and Witting J, 2007); the land robot whose stabilization mechanism was inspired by the tail movement of a jumping lizard (Chang-Siu et al., 2011); the self-moving endoscopes developed from the analysis of ragworms locomotion in slippery and tortuous substrates (Hesselberg, 
2007); and the flapping micro-air vehicles built from the mimesis of insects flight and size (Lentink et al, 2010).

Needless to mention how strong the link between the fields of computer science and biology is. For instance, after the emergence of genetic algorithms (Goldberg, 1998), many computational techniques inspired by nature have been proposed in the field of optimization, such as differential evolution ( $\mathrm{Li}$ and Yin, 2012), artificial bee colony (Karaboga and Basturk, 2007), particle swarm optimization (Kennedy, 2010), monarch butterfly optimization (Wang et al., 2015a), ant colony optimization (Zhang et al. 2014), firefly algorithm (Wang et al., 2014), chaotic cuckoo search (Wang et al., 2016a), earthworm optimization algorithm (Wang et al., 2015b), bat algorithm (Wang et al., 2016b), moth search algorithm (Wang, 2016), and krill herd algorithm (Wang et al., 2017).

The growth of biomimetic-related patents (Bonser, 2006) does reveal that the field of biomimetics is also gaining ground in the practical field. The benefits yielded by bio-inspired systems can be noticed in several applications, including structures, aerodynamics of vehicles, highly efficient devices and apparatus. By emulating dolphins' frequency-modulating acoustics, EvoLogics has developed a highperformance underwater modem for data transmission in harsh hydro-acoustic conditions. The device is currently employed in the tsunami early warning system throughout the Indian Ocean (www.evologics.de). This is only one example of successfully applied bio-inspired technology. It is enough to search on the internet for the term biomimicry to have a rough idea of the great amount of bio-inspired applications we are already surrounded by. Numerous research groups and laboratories around the world are currently active in the field of biomimicry and are engaged in outstanding projects.

\subsection{Sources of bio-inspiration for robust SHM}

Given its success in many different areas of engineering, biomimetics has recently been approached for SHM purposes. In this regard, biomimetics is guiding in the definition of new nature-inspired sensing paradigms for the development of highly efficient wireless sensor networks. The processing mechanisms used in biological sensory systems seem to be particularly attractive to engineers and scientists due to the simplistic individual functional unit, the neuron, which inevitably forms complex 
architectures with other units to convey information to the brain in real time (Modha et al., 2011). Networks of biological neurons are able to make extremely sophisticated decisions with reaction times in the millisecond range, and this is a very appealing feature for engineering applications that require real-time decision making (Peckens, 2014). In addition, neurons are capable of processing vast amounts of information at very fast rates with minimal energy costs thanks to highly compressive communication mechanisms. Various compressive methods for vibratory signals have been explored (Spanias et al., 1991; Zhang and Li, 2006; Bao et al., 2011; Bao et al., 2013; Mascarenas et al., 2013; Jayawardhana et al., 2017), but they are often computationally expensive and require complex post-processing steps, thus detracting from any real-time processing capabilities (Peckens and Lynch, 2013). Yet more, the need to perform numerous conversions between the analog and digital domains in conventional monitoring systems does inhibit the computational speed of the overall network.

By drawing inspiration from biology, new sensing and control methods may be formulated from which current engineered monitoring systems might largely benefit. In the last years, increasing efforts have been made in this direction, but further research is necessary. So far, the main sources of bio-inspiration that have found actuation in SHM can be grouped in three categories: central nervous system, cochlea system and immune system. In the next sections, a description of the key physiological mechanisms characterizing each biological model is presented, followed by a review of the relevant bio-inspired algorithms derived for SHM applications. The purpose is to provide a better comprehension on how the existing bio-inspired sensing paradigms have been conceived, what analogies between natural patterns and engineered SHM systems have been leveraged, if and how biological processes have been embedded into real software and hardware components, and which deficiencies still need to be addressed to ensure the design of optimal bio-inspired SHM solutions. Finally, for the sake of completeness, a brief overview of the status of bio-inspired sensing technology for the purpose of SHM is given.

4.3.1. Central nervous system. The central nervous system (CNS) is one of the most complex and fascinating sensory systems in human beings. Its adaptive architecture and parallel processing capabilities have repeatedly drawn the attention of mathematicians and engineers since decades. The 
main and essential organ of the CNS is the brain, which receives, integrates, coordinates and transmits information, operating together with the spinal cord. The core components of the brain and spinal cord are the neurons, electrically excitable cells connected to each other to form neural networks. A typical neuron is composed of three regions: the cell body (soma), the axon and the dendrites. The cell body, metabolic centre containing the nucleus of the cell, analyses the incoming signals; the axon, special cellular extension arising from the cell body, carries the signals to other neurons; the dendrites, treelike protrusions arising and branching from the cell body, receive the electrochemical signals from other cells' axons (figure 4). According to the 'neuron doctrine' proposed by Santiago Ramón y Cajal (Finger, 2000), neurons are not continuous throughout the body, yet still communicate with one another. The structure through which neurons pass signals to individual target cells is called synapse (from the Greek synapsis, meaning "conjunction"). Synapses can be excitatory or inhibitory and respectively increase or decrease the fire activity in the target neuron.

Each neuron receives information about an external stimulus through multiple receptors and encodes the information from this continuous input signal into a condensed format of all-or-none discrete electrochemical pulses called 'action potentials' or spike train, whose firing rate reflects the amplitude and frequency of the input (Bialek et al., 1991). If the action potentials exceed a certain threshold, an impulse is sent down the axon. The 'strength' of the synapse, a property which is not innate but subject to modification depending on the external signal, influences the effect of the impulse. When the impulse reaches the axon's terminal cell, neurotransmitters are released, activating the synaptic connection and transmitting the impulse to a multitude of receptors on the postsynaptic neurons. This results into a complete signal processing and information integration through complex networks of neurons (Kandel et al., 2000). The connections between these networks can be strengthened or weakened over time, thereby allowing the overall neural network to adapt according to input stimuli and to autonomously make sophisticated decisions (Kandel et al., 2000). It is worth noting that although the signal flows according to a serial architecture, the CNS relies on parallel components, thus enabling simultaneous processing of analogous information either in different groups of neurons or in different neurons of the same pathway. This innate multitasking skill guarantees efficiency, effectiveness, fault tolerance and provides the CNS with a global speed higher than a modern supercomputer. Furthermore, to minimize 
metabolic expense (energy) while maintaining rapid conduction, many neurons have insulating myelin sheaths around their axons. Extremely important is the role played by the glial cells, non-neural cells which constantly provide support and nutrition to neurons, insulate them electrically, maintain homeostasis, destroy pathogens and participate in the signal transmission within the nervous system. For a more comprehensive description of the physiology of the CNS the reader can refer to (Kandel et al., 2000).

Taking cue from the nature of the CNS, in the early 1940's Artificial Neural Networks (ANNs) were developed and implemented in computer software as an attempt to formulate mathematical representations of the basic physiology of an interconnected mesh of neurons. The first mathematical model of the neuron was introduced by the pioneering work of McCulloch and Pitts (1943). The authors conceived the neuron as an extremely simplified processing unit which fired only if the weighted sum of the inputs exceeded a certain threshold value $\alpha$ (all-or-none principle). According to this simplistic design known as the McCulloch-Pitts perceptron, the dendrites provide a set of $n$ inputs $x_{i}(i=1, \ldots, n)$, whereas the axon produces a single output $y$ which is the result of a linear activation function applied to the inputs (figure 5). The intent of the design was to model the axon-dendrite interactions of biological neural networks, where the activation function symbolized processing in the soma and the weights mimicked the synaptic strength between neurons. Although successful in capturing the threshold activation attribute of biological systems, the McCulloch-Pitts perceptron lacked the capability to make sophisticated decisions and was limited to linear applications. Shortly following this first work, different non-linear activation functions were developed (Bishop, 1994), such as the sigmoidal activation function. Hebb (1949) introduced variable weights, allowing the network to learn. Still, the earliest learning algorithms for neural networks and practical applications relied on adaptive synaptic connections (Rosenblatt, 1958; Widrow and Hoff, 1960), resulting effective only for a limited class of problems (Minsky and Seymour, 1969). In the 1980's, novel training algorithms based on error backpropagation were proposed in order to overcome these limitations (Rumelhart and McClelland, 1986). Since then, neural networks started to gain popularity and a great number of ANN-based methods appeared (Anderson and Rosenfeld, 1988; Anderson and Rosenfeld, 1990; Hagan et al., 2014). 
In what concerns the field of SHM, the multilayer perceptron (MLP) with sigmoidal activation function, trained by backpropagation to adjust weights and thresholds, has been the most common neural network architecture used hitherto (Doebling et al., 1996). Among other possible network architectures, interesting applications adopted cerebellar model articulation controller network (Yen and Kwak, 1993), counter propagation neural network (Hecht-Nielsen, 1988; Szewczyk and Hajela, 1994), probabilistic neural network (Jiang et al., 2011; Specht, 1990), radial basis function network (Rytter and Kirkegaard, 1997), and recurrent neural network (Butcher et al., 2014). Although the aforementioned ANN solutions were developed for the same purpose, their algorithms perform differently. For instance, Rytter and Kirkegaard (1997) proved that the MLP trained with backpropagation is more reliable than the radial basis function (RBF) network in damage identification, being the latter strongly dependent on the training examples. On the contrary, Amezquita-Sanchez and Adeli (2015) showed that the probabilistic neural network (PNN) far surpass the performance of the classic MLP thanks to lower training time and, according to $\mathrm{Li}$ (2011), the PNN also outclasses the learning vector quantization (LVQ) neural network when dealing with damage localization problems. Many real applications of ANN for SHM purposes have been reviewed in literature (Amezquita-Sanchez and Adeli, 2015; Fan and Qiao, 2011; Sohn et al., 2004; Carden and Paul, 2004; Doebling et al., 1996). Most works have shown the efficiency of neural networks as non-model-based methods for damage identification in the presence of training sets (supervised learning), but non-model-based unsupervised learning has also been attained through specific network architectures, such as the Self-Organizing Map, which are different from the feedforward architecture (Onur and Osama, 2015). One of the earliest work by Kudva et al. (1991) presented a two-step algorithm trained to identify location and size of a hole in a stiffened plate. Successively, other works applied the backpropagation neural network to locate and quantify damage in more complex systems, like multiple story buildings and trusses, after training the methods either with analytical solutions, finite element models or experimental data (Wu et al., 1992; Elkordy et al., 1993; Manning, 1994; Povich and Lim, 1994; Stephens and Van Luchene, 1994; Szewczyk and Hajela, 1994; Nakamura et al., 1998; Ni et al., 2006). Similarly, ANNs were used for bridge health monitoring to detect anomalies and assess damage extent (Chan et al., 1999; Feng and Bahng, 1999; Liu and Sun, 1997; Mehrjoo et al., 2008). However, when dealing with small local damages, ANNs 
resulted to be less reliable in terms of damage location and quantification (Kirkegaard and Rytter, 1994). In such cases, multi-stage artificial neural networks with sub-structuring have shown to be more suitable (Bakhar et al., 2010a; Bakhar et al., 2010b). It is noted that neural networks have also achieved good results in identifying damage patterns not belonging to training sets (unsupervised learning), which is essential for monitoring issues (Manning, 1994). Nevertheless, some authors prefer to use model-based approaches, e.g. model updating, when applying neural networks for damage localization and assessment in unsupervised learning (Chang et al., 1999; Sanders et al., 1997).

While the original intent of ANNs was to mimic the processing mechanisms employed by the nervous system, the evolution of these networks did actually diverge from the original source of inspiration. For example, the training techniques and the architectural design of ANNs have no link with the original biological neural circuit. Besides, ANNs are often used in combination with other methods to improve the reliability of the algorithm (Zheng et al., 2011), thus further deviating from the primary biological principles.

4.3.2. Cochlea system. Aiming at returning to the original principles of biological sensory systems, the mammalian cochlea system has recently been chosen as a source of inspiration for a new sensing paradigm for robust SHM, due to its unique processing techniques and real-time spectral decomposition capabilities (Elliott and Shera, 2012; Peckens and Lynch, 2013). The cochlea, namely the main signal processing unit of the auditory system, is a spiral-shaped tapered tube partitioned in three fluid-filled cavities by two elastic membranes: the Reissner's membrane and the basilar membrane (figure 6a-b). The latter is characterized by a geometric configuration and a mechanical stiffness which change along its length. As such, the natural frequency of the basilar membrane also varies along its length. When a sound wave enters the ear canal, or the outer ear, it excites the ear drum, which converts the sound wave into a pressure wave in the middle ear's fluid cavity. In turn, the pressure wave in the middle ear excites the inner ear's oval window, which is connected to the base of the cochlea (Yost, 1994). The frequency components in the signal selectively resonate sections of the basilar membrane whose local natural frequency is tuned to the same frequency of the signal component (Dallos, 1996). Based on the vibrating subsections of the membrane (figure 6c), the cochlea instantaneously maps out the frequency content 
of the signal and conveys the perceived stimulus to higher levels of the auditory cortex via neural signals (Peckens and Lynch, 2015). The stereocilia and associated inner hair cells (IHCs) of the organ of Corti, which runs on top of the basilar membrane (figure 6c-d), are responsible for encoding the analog response of the membrane, i.e. vibratory amplitudes, into compressed and asynchronous digital signals called 'binary spike trains' which are then transmitted to a unique set of auditory nerve fibers resulting in a finely tuned map of the motion of the basilar membrane (Yost, 1994). As the basilar membrane vibrates, the bundle of rigid sensory hairs (stereocilia) on top of each IHC deflects, allowing the release of transmitters across the auditory synapse which triggers a graded potential. The graded potential is then transmitted to the auditory nerve where its amplitude is encoded into a series of electrical spikes ('action potentials') whose firing rate is proportional to the velocity of the basilar membrane at the hair cell location. Being each electrical spike an all-or-none event, the spike will only fire if a threshold stimulus is reached and the resulting electrical spike will not carry information about the stimulus but instead will be part of a series of pulses that encode information about the perceived stimulus. Therefore, the central nervous system is able to determine the frequency content of the incoming sound wave depending on the activated nerve and also the associated amplitude through the firing rate of the neural spike train (Peckens and Lynch, 2015). In brief, the cochlea system utilizes a unique method of spectral decomposition, along with place theory (frequency-location mapping), to attain an impressive auditory range while maintaining near real-time processing capabilities. It is able to achieve this by acting as a hydro-mechanical frequency analyser, as well as using compressive techniques to efficiently transmit data to the CNS (Peckens and Lynch, 2013).

Based on the operational principles of the auditory system, a cochlea-inspired sensor was proposed by Peckens and Lynch (2013) in the context of signal processing for structural monitoring applications. The bio-inspired sensing system was conceived by mimicking the main data processing mechanisms of the mammalian cochlea: 1) spectral decomposition by the basilar membrane; and 2) linear encoding of peak values and data compression by the inner hair cells. These mechanisms were translated into an engineered sensor system by a two-step process: 1) decomposition of the vibratory signal into its frequency components through a bank of band-pass filters; and 2) implementation of a real-time peak picking algorithm with linear encoding of the filtered signals through an ultralow power microcontroller 
(figure 7). In the proposed sensor node, each band-pass filter represents a finite sub-section of the basilar membrane capable of extracting a specific frequency range from an input signal. If more filters are included in the system, the original signal results more detailed and better approximated but at the expense of increased compression rates. In order to determine the optimal filter bank configuration and reduce the distortion error, while minimizing information flow and energy consumption, Peckens and Lynch (2013) used a greedy search algorithm based on the minimization of an objective function. By doing this, they were able to design a cochlea-inspired sensor node with real-time processing capabilities and impressive data compression. The properties of the central nervous system, combined with the signal processing capabilities of the cochlea system, were then interpreted from an engineering viewpoint and their functionality was applied towards enhancing the performance of structural monitoring systems by giving rise to a resource efficient wireless sensor network architecture based on bio-mimicry of the CNS. Finally, by emulating the interactions between sensory neurons, motor neurons and muscles, a bio-inspired control algorithm was developed and validated on a four-story shear structure (Peckens, 2014). Nonetheless, a real application on a full-scale structure is needed to further validate this nature-inspired technology and demonstrate its real-time control capabilities in environments harsher than those afforded by controlled laboratory experiments.

Although successful in addressing many of the limitations and bottlenecks inherent to traditional wireless sensor nodes used for monitoring and control of civil infrastructures, the cochlea-inspired sensor node still presents room for improvement. In particular, two aspects deserve more investigation: the digital radio of the sensor, which is not able to modulate information in binary spike trains as seen within biological systems, thereby incurring unnecessary overhead; and the hardware architecture of the cochlea-inspired sensing node, which is not capable to 'learn' and autonomously adapt itself according to different input stimuli, similarly to the biological processes seen in nature.

4.3.3. Immune system. Another source of bio-inspiration which has drawn the attention of the scientific community for years is the human immune system. This system is composed by a set of different biological structures (i.e. tissues, organs and single cells) and processes, whose aim is to protect the body against potentially aggressive microorganisms and to limit the risk of disease. To this 
end, the first target of the immune system is to distinguish between self and non-self entities, discriminating and tackling the latter. Self-entities belong to the same organism of the immune system, whereas non-self entities are potential disease-causing agents, such as viruses, bacteria, parasites and fungi, scientifically labelled as pathogens.

The immune system operates through a multilevel defence of increasing specificity (Janeway et al., 2001). Most of infections are prevented without any symptom of disease by the first two levels of defence (external/internal epithelial surfaces and innate immune response), while the last level (adaptive immune response) is activated only when pathogens breach the first physical barriers of the host organism and successfully evade the innate response (figure 8). Essential for the adaptive response are the lymphocytes. Each lymphocyte bears receptors able to recognize and bind with specific molecular patterns called antigens (Janeway et al., 2001). The strength of this bond is called 'affinity'. Antigen specificity allows for the generation of responses that are tailored to specific pathogens or pathogen-infected cells. In detail, when a pathogen infects the body, lymphocytes mature and differentiate into effector cells so as to actively combat the infection. B lymphocytes differentiate into effector B-cells (plasma cells) which secrete antibodies able to signal pathogens; whereas $\mathrm{T}$ lymphocytes differentiate into effector T-cells (antigen-specific cells) which destroy infected cells (killer T-cells) or recruit and activate other cells (helper T-cells). After defeating the infection, most of effector cells undergo a programmed death (apoptosis), while the few cells that survive, the so-called 'memory cells', retain the tailored responses unfolded by the immune system ('immunological memory'), providing a faster and more effective response in case of a new contact with the same pathogen (Janeway et al., 2001).

Inspired by immunology, several adaptive problem-solving methods, and consequently algorithms, have been developed and collected under the name of Artificial Immune Systems (AISs), see De Castro et al., 1999. Following the analogies with its biological counterpart, each generic AIS requires the definition of several components which highly influence the effectiveness of the method, i.e.:

- Representation of data;

- Generation of detectors;

- Matching rules and affinity definition. 
According to the so-called shape-space approach (Perelson and Oster, 1979), the mathematical representation of the immune system's agents consists of either binary or real-valued strings, where the latter is much more suitable when dealing with SHM problems. Most of the methods, especially in realvalued representation, use random generation of detectors for discriminating between self and non-self entities (Ji and Dasgupta, 2007). However, there are also a few works in binary representation that make use of deterministic laws for the generation of detectors, based on the adopted matching rule (Ji and Dasgupta, 2007). Matching rules help to define the acceptable affinity level between monitoring data and AIS agents by setting a threshold, whose value strongly affects both the cost and reliability of the method. Specific evaluations about the problem addressed and its own self-space are always required in order to establish a threshold value for the affinity. A simple and general rule cannot be provided (Ayara et al., 2002).

Among the main algorithms derived from the mimicry of the functional principles of the immune system are negative and positive selection algorithms (figure 9), resulting from the evolution of the Self/Nonself discrimination theory formulated by Joshua Lederberg (1959). The first negative selection algorithm was developed by Forrest et al. (1994) and consisted of a binary coded method composed of two stages: the censoring of the generated detector matching sample normal condition data that belong to self-space, and the monitoring of data collected from the system to identify changes (Ayara et al., 2002). Initial real-valued algorithms presented approaches analogous to previous binary coded methods (González et al., 2002; Singh, 2003; Stibor et al., 2004). Afterwards, more efficient algorithms were developed in both representations (either binary or real-valued) for: i) generation of detectors with variable size, shape and centre position; ii) redundant detectors elimination; and iii) introduction of novel special features, such as guided high-rate mutation (De Castro and Timmis, 2002a) and clonation (Dasgupta et al., 2004). The main goal was to maximize the coverage of the non-self space (Ji and Dasgupta, 2004) while preventing overlapping of detectors. Variable radius algorithms were proposed in this regard by Matziger (2002), Ji and Dasgupta (2004) and Laurentys et al. (2010). Later on, further negative selection algorithms were developed (Ji and Dasgupta, 2007; Dasgupta et al., 2011), all differing in each of their components, viz. data representation, detectors generation and matching rules. The main advantage of this class of algorithms was that they only required normal condition data (Ji 
and Dasgupta, 2004). This is a very important feature in the majority of learning problems, since a complete knowledge of all possible fault conditions is usually not available. Thus, classical supervised SHM techniques often result less effective (González and Dasgupta, 2003). By applying negative selection-based methods, it is possible to achieve a first identification of an emerging damage scenario, just by recognizing it as the cause of an abnormal pattern of features. Despite the advantages, it is worth noting that constructing a detector set able to cover the entire non-self space is not possible for this type of algorithms, no matter what method is adopted (Wierzchoń, 2002).

Based on the clonal selection theory developed in the late 1970s by Burnet (1976), De Castro and Von Zuben (2002) proposed the first clonal selection algorithm (figure 9), named CLONALG. As already observed for negative selection algorithms, different approaches have been progressively suggested over time to improve the reliability of the initial clonal selection algorithm, e.g. resorting to real-valued representation (Campelo et al., 2005; Garrett, 2004), extending the applicability to multi-objective optimization (Luh et al., 2002; Ruochen et al., 2003), modifying clonal or mutation operators (Cutello et al., 2005; Garrett, 2004; Gong et al., 2007; Ruochen et al., 2003), or even introducing more operators (Cutello et al., 2005; Yu and Hou, 2004). Detailed reviews of this class of algorithms can be found in literature (Al-Enezi et al., 2010; Dasgupta et al., 2011).

A considerable step forward in the development of a bio-inspired theory of the immune system was made by Jerne (1974) and Hoffmann (1975), who tried to formalize the interacting network of immune system cells by leveraging their ability to mutually recognize each other and to create a dynamic system of self-stimulated elements, even in the absence of external aggressions. Unlike the theoretical basis, the numerical formulation for activation/suppression of cells within the network is not univocal and was formalized into a model only some years later by Farmer et al. (1986). This model did inspire the first Artificial Immune Network algorithm proposed by Ishida (1990) in the 1990s. Enhanced algorithms for data analysis and multimodal optimization were developed as well, like Jisys (Hunt et al., 1999), AINE (Timmis et al., 2000) and aiNET (De Castro and Von Zuben, 2001; De Castro and Timmis, 2002b), an artificial immune network formally inspired by the clonal selection.

Altogether, AIS-based methods present several strengths. Among the main advantages are the distributed and imperfect detections. The former provides a good coverage of both self and non-self 
spaces even without a centralized management, making self-organization and communication within detectors possible. The latter permits detectors flexibility, allowing to reduce the number of detectors in the identification process since a perfect matching is not required. Moreover, AIS methods are endowed with adaptability, being easily improved to learn not only in the initial training stage, but also in the following monitoring stages.

The numerous benefits of immune-inspired methods have boosted their use in different fields, such as Computer and Network Security, Anomaly and Fault Detection, Pattern Recognition, Data Mining Clustering and Filtering, Machine Learning, Function Optimization, and many others (Aickelin et al., 2014; De Castro et al., 1999). AIS architectures have also been developed and successfully applied in the field of mechanical engineering for condition monitoring purposes (Bayar et al., 2015), but just a few works have extended the results to SHM applications in civil engineering, even though these two fields present various common characteristics. An example is the work of Chen and Zang (2009) who, based on previously developed algorithms, i.e. CLONALG (De Castro and Von Zuben, 2002) and AIRS (Watkins et al., 2004), formulated an Artificial Immune Pattern Recognition (AIPR) method in order to identify, by similarities, the class of an a priori known damage (supervised pattern recognition problem). Relying on Fuzzy Clustering algorithm, a few years later the same authors provided an unsupervised damage classification algorithm able to distinguish among different damage classes, each represented by a specific memory cell, according to the similarity in the monitored data (Bo and Zang, 2009). The AIPR structural damage classification was then integrated into an automatic immuneinspired monitoring system composed of mobile agents mimicking B-cells, which patrolled over a wireless network of different sensors distributed throughout the monitored structure (Chen, 2010; Liu and Chen, 2011). Finally, the AIPR method was upgraded to allow for anomaly identification even in the absence of specific data sample in the training stage (Chen and Zang, 2011), thereby enabling to solve unsupervised pattern recognition problems. Other examples in the field of immune-inspired SHM are: the work of Xiao (2012), who proposed a method for fault diagnosis trained to identify specific damage locations and extents through the combination of negative and clonal selections; the work of Abbasidoust et al. (2012), who developed a damage detection model-based AIS algorithm with weighted attributes that relies on clonal and negative selection algorithms; and the recent works of 
Anaya et al. $(2014 ; 2015)$, who presented an active system for structural damage detection based on the use of piezoelectric transducers acting either as actuators or sensors. In this last case, different data patterns belonging to known damage conditions were employed to train the method, according to a clonal selection strategy. It is noted that clonal selection and immune network theories are strongly reliable and effective in tackling optimization problems. In fact, they both inspired algorithms for improving the distribution of sensors in the monitoring of civil engineering systems (Yi et al., 2015; Zhang et al., 2008). However, when dealing with damage identification problems, most of clonal selection and immune network algorithms allow to identify damage location and extent only if they are correctly trained to recognize the features of a given damage state or when, in case of supervised process, a label to the emerged damage is assigned for future recognition. This is one of the main issues to address in order to exploit immune-inspired techniques for both supervised and unsupervised SHM and foster their use in civil engineering applications.

With the purpose of improving setting and effectiveness of the method, the evolution of AISs did ultimately deviate from the original source of inspiration, as seen for ANNs. In some cases, mutation and clonation operators are integrated with Fuzzy logic (Leng and Bentwich, 2002; Costa Silva et al., 2012) or, alternatively, randomized algorithms like Monte Carlo integration (González et al., 2003) are used together with the original immune-inspired algorithms. In other cases, AIS-based algorithms are combined with non-bio-inspired models, e.g. Bayesian network (De Castro and Von Zuben, 2009), further preventing from the complete actuation of the initial bio-inspired paradigm.

4.3.4. Other emerging sources of bio-inspiration. Besides the three major sources examined hitherto, other sources of bio-inspiration have gained ground within the research community involved in the field of SHM, especially in the computational area. In particular, the Darwinian principles of natural evolution have inspired the class of evolutionary algorithms (EAs) which have been used in the field of SHM and damage identification for solving optimization problems, such as best sensor placement, network coverage and mobile sensor deployment (Abbasi et al., 2014). Among EAs, genetic algorithms (GAs) have been quite extensively investigated (Yi et al., 2011; Huang et al., 2016; Silva et al., 2016). However, the processes of these particular genetic operators are complex, and the computational 
efficiency is low. To overcome these limitations, various attempts have been made, including the introduction of the virus evolutionary theory into the GA.

The promising application of GAs in the sensor network design for SHM systems has rapidly led to the application of other intelligent approaches, such as particle swarm optimization (PSO) and ant colony optimization (ACO), the former conceived after the social behaviour of bird flocking or fish schooling and the latter inspired by the behaviour of real ants and their pheromone trail-based communication scheme. These algorithms are currently among the most established population-based metaheuristics that have been employed with some success in the field of SHM, typically when dealing with best sensor placement and coverage optimization $(\mathrm{Li}, 2012)$ or damage detection problems (Qian et al., 2012; Perera et al., 2014; Yu and Xu, 2011). However, in most of these approaches, either the considered network characteristics are very limited, or several requirements of the application cases are not incorporated into the performance measure of the algorithm. To maximize the performance (detection) while minimizing the cost of the sensor system, Yi et al. (2012) explored the modified monkey algorithm (MA), a kind of evolutionary algorithm designed after the mountain-climbing processes of monkeys. Shortly following this first attempt, an enhanced version of the MA, i.e. the asynchronous-climb monkey algorithm (AMA), was proposed by the same authors and experimentally verified for the optimum design of sensor arrays in the Canton Tower in Shanghai (Yi et al., 2015).

Another interesting source of bio-inspiration which has been transplanted into an SHM system is the deoxyribonucleic acid (DNA) array (Lin et al., 2010). The proposed system is constructed utilizing a double-tier regression process to extract the expression array from the structural time history recorded during external excitations. This array is symbolized as the various genes of the structure from the viewpoint of molecular biology and reflects the possible structural damage conditions. The DNAinspired SHM system was tested on a scaled-down six-story steel building, showing satisfactory results in terms of damage detection.

Shifting from computing to sensing technologies, the unique functionalities and properties of the skin of humans, animals, and insects have led to active research in developing skin-inspired tactile sensors as well as distributed strain sensors that take advantage of nanotechnology-derived materials (Loh et al., 2015). In particular, in the context of SHM, skin-like distributed sensing coupling piezoresistive 
CNT (carbon nanotubes)-based thin films (fabricated using layer-by-layer assembly) with an electrical impedance tomography (EIT) algorithm have been achieved for strain monitoring and damage detection purposes (Loh and Azhari, 2012). Inspired by natural hair cells and their diversity, further studies have aimed at developing flow sensors that mimic the mechanisms evolved and perfected in sensory hairs. Artificial hair cells (AHCs) perform electromechanical transduction in response to air or fluid flow, similar to the way tilting of biological hair cells results in neuronal electrical signals. A specific application in which bio-inspired flow sensors have been used for SHM is the case of bridge scour monitoring. In fact, to overcome the limitations imposed by conventional scour detection methods, Swartz et al. (2014) proposed a modular wireless smart scour sensing post consisting of bio-inspired, whisker-shaped magnetostrictive flow sensors able to detect water flow by bending and to wirelessly transmit the response to a base station in real time.

Although skin-inspired sensors offer the possibility to monitor the structural behaviour at fine-grained level and to resolve changes throughout the system simultaneously, the costs associated with such a densely distributed and multimodal sensing technology may be prohibitive. Hence, extensive research is being devoted to the development of biomimetic crawling/climbing sensors emulating different creatures' ability to navigate around the world in order to minimize the number of sensors to deploy over a structure while still ensuring optimum coverage and accuracy in damage detection. A successful example used for SHM applications is the mobile sensor that Zhu et al. (2010) created by connecting two two-wheeled vehicles through a flexible beam, with an accelerometer placed on its centre, to collect the vibration response of a steel portal frame subjected to damage. The snake-like robot proposed by Enner et al. (2013) to monitor pipeline systems is another practical example that outlines the diversity of current bio-inspired research activities.

While the variety of bio-inspired algorithms and sensors developed so far allow to tackle individual SHM-related aspects, the complexity of the SHM process requires a more holistic approach, where each single instance is not addressed separately, but only by reference to the whole. Hence, in parallel to these engineering advancements, more in-depth understanding of biological systems and relevant assemblies are essential for driving new scientific and technological breakthroughs in bio-inspired sensor research. 


\section{A framework for new bio-inspired sensing paradigms in SHM}

The previous section has shown how uncovering the general principles behind the functioning of selected biological systems can lead to the development of efficient solutions to the technical conflicts and operational problems of actual SHM architectures. It must be stressed that the intrinsic nature of biology and engineering is very different and the transfer of concepts or mechanisms from living to non-living systems is not trivial (Vincent et al., 2006). Organisms are the result of a millenary evolution process moulded by natural selection; engineered systems are the product of a decision-making process driven by prescriptions. A simple and direct replica of the biological prototype is rarely successful and some form or procedure of interpretation and translation from biology to technology is always required (Vincent et al., 2006). As shown in Section 4, significant contributions to the definition of suitable bioinspired paradigms for SHM applications have been produced in the last decade. However, more research is needed in this field in order to enhance 'already (but not completely)-addressed' technical aspects and to keep on searching for solutions to the issues yet to be tackled.

The scope of this section is to provide a dialectic framework to help identify analogous features between biological and SHM systems and to easily discriminate desired from unwanted nature-inspired characteristics. Such a framework will ultimately assist in seeking for the most suitable and robust synthesis to the dialectics. This pairing process is materialized into a compatibility-matrix with the desired SHM system's characteristics distributed along the top and the identified biological features arranged along the vertical axis (see Table 1). At this stage, only the three main sources of bioinspiration that have been discussed in Section 4.3 are considered for the analogy. The biological subsystem in charge of each specific physiological function is listed as well, together with the engineered version of the relevant biomimetic system, when existing. As for the attributes of the SHM system, they have been listed grounded on the critical appraisal and considerations emerged from the previous sections. The outlined compatibility-matrix aims at driving the selection of the most compatible and wanted functions to transfer from nature to SHM. Each 'problem' is defined by a pair of analogous characteristics (e.g. 'data fusion' for the SHM system and 'information integration' for the biological 
system). However, the feature matching is not univocal, since each characteristic of the monitoring system can have more than one functional analogy with the biological counterpart. The stronger the compatibility (analogy), the stronger the future solution.

Hitherto, most bio-inspired paradigms have been conceived and developed for reasons other than health monitoring and structural control. On the contrary, the main idea behind the proposed dialectic matrix moves from an inverse approach. Instead of browsing biological literature to find one potential prototype and try to adjust it for emulation into some artificial system, which may likely turn out to be useful for SHM applications, now the target is to start first with the identification of all desirable properties and functions a robust SHM system must be provided with. Only in the second place one should look for functional analogies in biology in order to understand how nature has addressed similar instances and how an artificial system can be modelled on a very complex natural prototype to imitate its functional principles as closely as possible. The bio-inspired analogies that have already found actuation in SHM are not many, as shown in Table 1, column 'Biomimetic System'. Greater efforts are needed in this field to fill existing gaps.

Although limited, the proposed compatibility-matrix can be considered as the first attempt to systematize and tailor biomimetics to SHM requirements (and not vice versa) according to a holistic approach, where architectural and networking issues are not addressed separately but as a unified whole. The next step will be to increase the order of the matrix by including new biological functions that match the desired SHM system's characteristics. In such a way the remaining gaps can be filled (e.g. the SHM attributes marked by grey cells in the matrix still have no matching) and a wider range of analogies can be obtained for the same engineered feature. Finally, the functional analogies showing the closest fit will be analysed in detail and sorted by levels of complexity to enable the selection of the best bio-inspired solutions, both in terms of performance and feasibility, for the subsequent implementation into biomimetic multimodal engineered systems for SHM and control.

\section{Conclusions}

This paper has reviewed important research developments in the field of bio-inspired computation for structural health monitoring, along with some recent advancements in bio-inspired sensing technology 
for SHM. First, a critical analysis of current state-of-the-art approaches to SHM has been provided to demonstrate the need for bio-inspired design in this field. Second, the functional principles of the three main biological systems that have given rise to bio-inspired artificial counterparts in SHM have been detailed to foster a better comprehension of the functional analogies between biological and SHM systems.

Recent advancements in bio-inspired computation have permitted the development of various algorithms for best sensor placement, optimal network coverage, compressive sensing and damage detection. However, such computational tools still require expensive and tedious materials processing. In what concerns bio-inspired sensing technology, the latest advancements include skin-like and mobile sensors aimed at creating multimodal densely distributed and scalable SHM system to measure the structural response at fine-grained level and improve accuracy in terms of damage identification.

The scope of this paper has been limited to presenting an overview of selected works for bio-inspired SHM. The analysed papers reveal that biomimetics is still largely empirical and lacks a systematic approach. In general, the majority of bio-inspired paradigms were conceived for reasons other than structural monitoring and, despite the numerous attempts of biomimicry, most artificial systems either remained inferior to their natural counterparts or diverged from the primary source of inspiration. To get back to the original bio-inspired principles, more in-depth analyses of the parallels between biological kingdom and SHM systems are necessary to be able to tailor biomimetics to SHM requirements and achieve high performance sensor networks. A holistic approach must be leveraged, where networking and architectural issues are not addressed separately. To this end, the authors propose a compatibility-matrix derived from the careful analysis of the key physiological mechanisms of three sources of bio-inspiration, i.e. central nervous system, cochlea system and immune system. Such matrix draws interesting conclusions in terms of feature matching between natural and artificial counterparts and provides compelling evidence for a holistic bio-inspired design in SHM. Hence, it is expected that bio-inspired research in the field of SHM will continue to grow exponentially, not only trying to mimic single biological functionalities, but also aiming at creating integrated full SHM systems assembled in the same manner as in biology. 


\section{References}

Abbasi, M., Bin Abd Latiff, M.S. and Chizari, H. (2014) 'Bioinspired evolutionary algorithm based for improving network coverage in wireless sensor networks', The Scientific World Journal, Vol. 2014, Article ID 839486, 8 pages.

Abbasidoust, F., Lotfollahi-Yaghin, M., Sadeghi, M.H., Mojtahedi, A., Ettefagh, M.M. and Hassanzadeh, Y. (2012) 'A robust damage detection method developed for offshore jacket platforms using modified artificial immune system algorithm', China Ocean Engineering, Vol. 26 No. 3, pp. 379395.

Abdaoui, A., El Fouly, T.M. and Ahmed, M.H. (2017) 'Impact of time synchronization error on the mode-shape identification and damage detection/localization in WSNs for structural health monitoring', Journal of Network and Computer Applications, Vol. 83, pp. 181-189.

Aickelin, U., Dasgupta, D. and Gu, F. (2014) 'Artificial immune systems' in Burke, E.K. and Kendall, G. (Eds.), Search Methodologies: Introductory Tutorials in Optimization and Decision Support Techniques, Springer, New York, pp. 187-211.

Al-Enezi, J.R., Abbod, M.F., and Alsharhan, S. (2010) 'Artificial immune systems - models, algorithms and applications', International Journal of Recent Research and Applied Studies, Vol. 3 No. 2, pp. 118 131.

Alonso, L., Barbarán, J., Chen, J., Díaz, M., Llopis, L. and Rubio, B. (2018) 'Middleware and communication technologies for structural health monitoring of critical infrastructures: A survey', Computer Standards \& Interfaces, Vol. 56, pp. 83-100.

Amezquita-Sanchez, J.P. and Adeli, H. (2015) 'Feature extraction and classification techniques for health monitoring of structures', Scientia Iranica. Transaction A, Civil Engineering, Vol. 22 No. 6, pp. 1931-1940.

Anaya, M., Tibaduiza, D. and Pozo, F. (2014) 'Data driven methodology based on artificial systems for damage detection' Paper Presented at the EWSHM 7th European Workshop on Structural Health Monitoring. 8-11 July, 2014. Nantes, France.

Anaya, M., Tibaduiza, D.A. and Pozo, F. (2015) 'A bioinspired methodology based on an artificial immune system for damage detection in Structural Health Monitoring', Shock and Vibration, Vol. 2015.

Anderson, J.A. and Rosenfeld, E. (1988) Neurocomputing: foundations of research, MIT Press, Cambridge.

Anderson, J. and Rosenfeld, E. (1990) Neurocomputing: directions for research, MIT Press, Cambridge.

Ayara, M., Timmis, J., De Lemos, R., De Castro, L.N. and Duncan, R. (2002) 'Negative selection: how to generate detectors' in Proceedings of the first International Conference on Artificial Immune Systems ICARIS 2002, University of Kent at Canterbury Printing Unit, Canterbury, pp. 182-196.

Ayers, J. and Witting, J. (2007) 'Biomimetic approaches to the control of underwater walking machines', Philosophical Transactions of the Royal Society of London, Series A: Mathematical, Physical and Engineering Sciences, Vol. 365 No. 1850, pp. 273-295.

Avci, O., AbdeljabeR O., Kiranyaz, S., Hussein, M. and Inman, D.J. (2018) 'Wireless and real-time structural damage detection: A novel decentralized method for wireless sensor networks', Journal of Sound and Vibration, Vol. 424, pp. 158-172.

Bakhary, N., Hao, H. and Deeks, A.J. (2010a) 'Structure damage detection using neural network with multi-stage substructuring', Advances in Structural Engineering, Vol. 13 No. 1, pp. 95-110.

Bakhary, N., Hao, H. and Deeks, A.J. (2010b) 'Substructuring technique for damage detection using statistical multi-stage artificial neural network', Advances in Structural Engineering, Vol. 13 No. 4, pp. 619-639. 
Bampton, M.C.C., Ramsdell, J.V., Graves, R.E. and Strope, L.A. (1986) Deer Isle-Sedgwick suspension bridge. Wind and motion analysis, Report no FHWA/RD-86/183.

Bao, Y., Beck, J.L. and Li, H. (2011) 'Compressive sampling for accelerometer signals in structural health monitoring', Structural Health Monitoring, Vol. 10 No. 3, pp. 235-246.

Bao, Y., Li, H., Sun, X., Yu, Y. and Ou, J. (2013) 'Compressive sampling-based data loss recovery for wireless sensor networks used in civil structural health monitoring', Structural. Health Monitoring, Vol. 12 No. 1, pp. 78-95.

Barr, B.I.G., Waldron, P. and Evans, H.R. (1987) 'Instrumentation of glued segmental box girder bridges', in Proceedings of IABSE colloquium, monitoring of large structures and assessment of their safety, Bergamo, Italy.

Barthlott, W. and Neinhuis, C. (1997) 'Purity of the sacred lotus, or escape from contamination in biological surfaces’, Planta, Vol. 202 No. 1, pp. 1-8.

Bayar, N., Darmoul, S., Hajri-Gabouj, S. and Pierreval, H. (2015) 'Fault detection, diagnosis and recovery using artificial immune systems: a review', Engineering Applications of Artificial Intelligence, Vol. 46, pp. 43-57.

Bechert, D.W., Bruse, M., Hage, W. and Meyer, R. (2000) 'Fluid mechanics of biological surfaces and their technological application', Naturwissenschaften, Vol. 87 No. 4, pp. 157-171.

Behnia, A., Chai, H.K. and Shiotani, T. (2014) 'Advanced structural health monitoring of concrete structures with the aid of acoustic emission', Construction and Building Materials, Vol. 65, pp. 282302.

Bensky, A. (2004) Short-range wireless communication, 2nd ed., Elsevier, Amsterdam.

Bialek, W., Rieke, F., de Ruyter Van Steveninck, R.R., and Warland, D. (1991) 'Reading a neural code', Science, Vol. 252 No. 5014, pp. 1854-1857.

Bishop, C.M. (1994) 'Neural networks and their applications', Review of scientific instruments, Vol. 65 No. 6, pp. 1803-1832.

Bo, C. and Zang, C. (2009), 'Unsupervised structure damage classification based on the data clustering and artificial immune pattern recognition' in Proceedings of the 8th International Conference on Artificial Immune Systems ICARIS 2009, Springer-Verlag, Berlin, pp. 206-219.

Bonser, R.H. (2006) 'Patented biologically-inspired technological innovations: a twenty-year view', Journal of Bionic Engineering, Vol. 3 No. 1, pp. 39-41.

Brederode, P., De Winter, P., Van Staalduinen, P. and Segers, W. (1986) 'Dynamic offshore structure test (DOST) project - a new approach to quality assessment of offshore structures', in Proceedings of the conference on Inspection, repair and maintenance IRM/AODC86.

Brownjohn, J.M.W. (2007) 'Structural health monitoring of civil infrastructure', Philosophical Transactions of the Royal Society of London A: Mathematical, Physical and Engineering Sciences, Vol. 365 No. 1851, pp. 589-622.

Burnet, F.M. (1976) 'A modification of Jerne's theory of antibody production using the concept of clonal selection', CA: A Cancer Journal for Clinicians, Vol. 26 No. 2, pp. 119-121.

Butcher, J., Day, C., Austin, J., Haycock, P., Verstraeten, D. and Schrauwen, B. (2014) 'Defect detection in reinforced concrete using random neural architectures', Computer-Aided Civil and Infrastructure Engineering, Vol. 29 No. 3, pp. 191-207.

Campelo, F., Guimaraes, F., Igarashi, H. and Ramirez, J. (2005) 'A clonal selection algorithm for optimization in electromagnetics', IEEE Transactions on Magnetics, Vol. 41 No. 5, pp. 1736-1739.

Carden, E.P. and Brownjohn, J.M.W. (2008) 'ARMA modelled time-series classification for structural health monitoring of civil infrastructure', Mechanical Systems and Signal Processing, Vol. 22 No. 2, pp. 295-314. 
Carden, E.P. and Paul, F. (2004) 'Vibration based condition monitoring: a review', Structural Health Monitoring, Vol. 3 No. 4, pp. 355-377.

Chan, T., Ni, Y. and Ko, J. (1999) 'Neural network novelty filtering for anomaly detection of Tsing Ma bridge cables' in Chang, F.K. (Ed.), Structural Health Monitoring 2000, Technomic publication, Lancaster, pp. 430-439.

Chang, F-K. (2000) A summary report of the 2nd workshop on structural health monitoring held at Stanford University on September 8-10, 1999, Report no. AO83483, Department of Aerounatics and Astronautics Stanford University, CA, USA.

Chang, T., Chang, C. and Xu, Y. (1999) 'Updating structural parameters: an adaptive neural network approach' in Chang, F-K (Ed), Structural Health Monitoring 2000, Technomic Publishing Company, Lancaster, pp. 379-389.

Chang-Siu, E., Libby, T., Tomizuka, M. and Full, R.J. (2011) 'A lizard-inspired active tail enables rapid maneuvers and dynamic stabilization in terrestrial robot' in Proceedings of 2011 IEEE/RSJ International Conference on Intelligent Robots and Systems IROS 2011, pp. 1887-1894.

Chen, B. (2010) 'Agent-based artificial immune system approach for adaptive damage detection in monitoring networks', Journal of Network and Computer Applications, Vol. 33 No. 6, pp. 633-645.

Chen, B. and Zang, C. (2009) 'Artificial immune pattern recognition for structure damage classification', Computers and Structures, Vol. 87 No. 21, pp. 1394-1407.

Chen, B. and Zang, C. (2011) 'Emergent damage pattern recognition using immune network theory', Smart Structures and Systems, Vol. 7 No. 6, pp. 69-92.

Chen, J., Díaz, M., Llopis, L., Rubio, B. and Troya, J.M. (2011) 'A survey on quality of service support in wireless sensor and actor networks: Requirements and challenges in the context of critical infrastructure protection', Journal of Network and Computer Applications, Vol. 34 No. 4, pp. 12251239.

Cheung, M.S., Tadros, G.S., Brown, T., Dilger, W.H., Ghali, A. and Lau, D.T. (1997) 'Field monitoring and research on performance of the Confederation Bridge', Canadian Journal of Civil Engineering, Vol. 24 No. 6, pp. 951-962.

Chiu, W.K., Galea, S.C., Koss, L.L. and Rajic, N. (2000) 'Damage detection in bonded repairs using piezoceramics', Smart Materials and Structures, Vol. 9 No. 4, pp. 466-475.

Clegg, W.J., Kendall, K., Alford, N.M., Button, T.W. and Birchall, J.D. (1990) 'A simple way to make tough ceramics', Nature, Vol. 347 No. 6292, pp. 455-457.

Comanducci, G., Ubertini, F. and Materazzi, A.L. (2015) 'Structural health monitoring of suspension bridges with features affected by changing wind speed', Journal of Wind Engineering and Industrial Aerodynamics, Vol. 141, pp. 12-26.

Comerford, J.B., Salvaneschi, P., Lazzari, M., Bonaldi, P., Ruggeri, G., Fanelli, M., Giusepetti, G. and Mazza, G. (1992) 'The role of AI technology in the management of dam safety: the DAMSAFE system', Dam Engineering, Vol. 3 No. 4, pp. 215-226.

Coppolino, R.N. and Rubin, S. (1980) 'Detectability of structural failure in offshore platforms by ambient vibration monitoring' in $12^{\text {th }}$ annual Offshore Technology Conference vol 4, pp. 101-110.

Costa Silva, G., Martinez Palhares, R. and Matos Caminhas, W. (2012) 'Immune inspired fault detection and diagnosis: a fuzzy-based approach of the negative selection algorithm and participatory clustering', Expert Systems with Applications, Vol. 39 No. 16, pp. 12474-12486.

Cross, E.J., Koo, K.Y., Brownjohn, J.M.W. and Worden, K. (2013) 'Long-term monitoring and data analysis of the Tamar Bridge', Mechanical Systems and Signal Processing, Vol. 35 No. 1-2, pp. 1634. 
Cutello, V., Narzisi, G., Nicosia, G. and Pavone, M. (2005) 'An immunological algorithm for global numerical optimization' in Artificial Evolution: 7th Int. Conference, Evolution Artificielle EA 2005, Springer-Verlag, Berlin, pp. 284-295.

Dallos, P. (1996) 'Overview: cochlear neurobiology' in Dallos, P., Popper, A.N. and Fay, R.R. (Eds.), The Cochlea (Springer Handbook of Auditory Research), Springer- Verlag, New York, pp. 1-43.

Darbre, G.R. and Proulx, J. (2002) 'Continuous ambient-vibration monitoring of the arch dam of Mauvosin’, Earthquake Engineering \& Structural Dynamics, Vol. 31 No. 2, pp. 475-480.

Dasgupta, D., Krishna Kumar, K., Wong, D. and Berry, M. (2004) 'Negative selection algorithm for aircraft fault detection' in Proceedings of Third International Conference on Artificial Immune Systems ICARIS 2004, Springer-Verlag, Berlin, pp. 1-13.

Dasgupta, D., Yu, S. e Nino, F. (2011) 'Recent Advances in Artificial Immune Systems: Models and Applications', Applied Soft Computing, Vol. 11 No. 2, pp. 1574-1587.

De Castro, L.N., Nunes, L. and Von Zuben, F.J. (1999) Artificial immune systems: Part I-basic theory and applications, Report no. TR - DCA 01/99, Universidade Estadual de Campinas, Brasil.

De Castro, L.N. Timmis, J. (2002a) Artificial immune systems: a new computational intelligence approach. Springer Science \& Business Media, New York.

De Castro, L.N. and Timmis, J. (2002b) 'An artificial immune network for multimodal optimization' in Proceedings of the 2002 Congress on Evolutionary Computation CEC 2002.

De Castro, L.N. and Von Zuben, F.J (2001) 'AiNet: an artificial immune network for data analysis' in Abbass, H.A., Sarker, R.A. and Newton, C.S. (Eds.), Data Mining: A Heuristic Approach, Idea Group Publishing, USA, pp. 231-259.

De Castro, L.N. and Von Zuben, F.J. (2002) 'Learning and optimization using the clonal selection principle', IEEE transactions on evolutionary computation, Vol. 6 No. 3, pp. 239-251.

De Castro, P.A.D. and Von Zuben, F.J. (2009) 'A bayesian artificial immune system for the effective handling of building blocks', Information Sciences, Vol. 179 No.10, pp. 1426-1440.

Doebling, S.W., Farrar, C.R., Prime, M.B. and Shevitz, D.W. (1996) Damage identification and health monitoring of structural and mechanical systems from changes in their vibration characteristics: a literature review, Report for the National Laboratory LA-13070-MS, Los Alamos.

Elkordy, M., Chang, K. and Lee, G. (1993) 'Neural network trained by analytically simulated damage states', ASCE Journal of Computing in Civil Engineering, Vol. 7 No. 2, pp. 130-145.

Elliott, S.J. and Shera, C.A. (2012) 'The cochlea as a smart structure', Smart Materials and Structures, Vol. 21 No. 6, pp. 064001.

Enner, F., Rollinson, D. and Choset, H. (2013) 'Motion estimation of snake robots in straight pipes' in IEEE International conference on robotics and automation (ICRA), Karlsruhe, Germany, pp. 51495153.

EvoLogics. [online] www.evologics.de (accessed on May 2016).

Fan, W. and Qiao, P. (2011) 'Vibration-based damage identification methods: a review and comparative study’, Structural Health Monitoring, Vol. 10 No. 1, pp. 83-111.

Fanelli, M.A. (1992) 'The safety of large dams', in Blockley D. (Ed.), Engineering Safety. McGrawHill, Berkshire, UK, pp. 205-223.

Farmer, D.J., Packard, N.H. and Perelson, A.S. (1986) 'The immune system, adaptation and machine learning', Physica D: Nonlinear Phenomena, Vol. 22 No. 1, pp. 187-204.

Farrar, C.R., Sohn, H., Hemez, F.M., Anderson, M.C., Bement, M.T., Cornwell, P.J., Doebling, S.W., Lieven, N., Robertson, A. and Schultze, J. (2003) Damage prognosis: current status and future needs, Technical Report No. LA-14051-MS. Los Alamos National Laboratory, Los Alamos, NM, US. 
Farrar, C.R. and Worden, K. (2007) 'An introduction to structural health monitoring', Philosophical Transactions of the Royal Society, Series A: Mathematical, Physical and Engineering Sciences, Vol 365 No.1851, pp. 303-315.

Farrar, C.R. and Lieven, N.A.J. (2007) 'Damage prognosis: the future of structural health monitoring', Philosophical Transactions of the Royal Society, Series A: Mathematical, Physical and Engineering Sciences, Vol. 365 No.1851, pp. 622-632.

Feng, M.Q. and Bahng, E.Y. (1999) 'Damage assessment of jacketed RC columns using vibration test', Journal of Structural Engineering, Vol. 125 No. 3, pp. 265-271.

Finger, S. (2000) 'Santiago Ramon y Cajal. From nerve nets to neuron doctrine', in Finger, S. (Ed), Minds behind the brain: A history of the pioneers and their discoveries, Oxford University Press, New York, pp. 197-216.

Forrest, S., Perelson, A.S., Allen, L. and Cherukur, R. (1994) 'Self-nonself discrimination in a computer' Paper Presented at the IEEE Computer Society Symposium on Security and Privacy. 16-18 May 1994. Oakland, CA, USA.

Gao, H.J. (2006) 'Application of fracture mechanics concepts to hierarchical biomechanics of bone and bone-like materials', International Journal of Fracture, Vol. 138 No. 1-4, pp. 101-137.

Garrett, S. (2004) 'Parameter-free adaptive clonal selection' Paper Presented at the Congress on Evolutionary Computation CEC2004. 19-23 June 2004. Portland, OR, US.

Giurgiutiu, V. (2014) Structural health monitoring with piezoelectric wafer active sensors, 2th ed., Academic Press.

Goldberg, D.E. (1998) 'Genetic algorithms in search, optimization and machine learning', AddisonWesley, New York.

Gong, M., Jiao, L., Zhang, L. and Ma, W. (2007) 'Improved real-valued clonal selection algorithm based on a novel mutation method' in Proceedings of 2007 International Symposium on Intelligent Signal Processing and Communication Systems.

González, F. and Dasgupta, D. (2003) 'Anomaly detection using real-valued negative selection', Genetic Programming and Evolvable Machines, Vol. 4 No. 4, pp. 383-403.

González, F., Dasgupta, D. and Kozma, R. (2002) 'Combining negative selection and classification techniques for anomaly detection' in Proceedings of the 2002 Congress on Evolutionary Computation CEC2002.

González, F., Dasgupta, D. and Niño, L.F. (2003), 'A randomized real-valued negative selection algorithm' in Proceedings of Second International Conference on Artificial Immune System ICARIS 2003, Springer-Verlag, Berlin, pp. 261-272.

Hagan, M.T., Demuth, H.B., Beale, M.H. and De Jesús, O. (2014) Neural network design, 2nd ed.

Harkness, J.M. (2002) 'A lifetime of connections-Otto Herbert Schmitt, 1913-1998', Physics in Perspective, Vol. 4 No. 4, pp. 456-490.

Hebb, D.O. (1949) The organization of behavior, Wiley, New York.

Hecht-Nielsen, R. (1988) 'Applications of counterpropagation networks', Neural Networks, Vol. 1 No. 2, pp. 131-139.

Hesselberg, T. (2007) 'Biomimetics and the case of the remarkable ragworms', Naturwissenschaften, Vol. 94 No. 8, pp. 613-621.

Hoffmann, G.W. (1975) 'A network theory of the immune system', European Journal of Immunology, Vol. 5 No. 9, pp. 638-647.

Huang, Y., Ludwing S.A. and Deng, F. (2016) 'Sensor optimization using a genetic algorithm for structural health monitoring in harsh environments', J Civil Struct Health Monit, Vol. 6 No. 3, pp. 509519. 
Hunt, J., Timmis, J., Cooke, E., Neal, M. and King, C. (1999) 'Jisys: the envelopment of an artificial immune system for real world applications', in Dasgupta, D. (Ed.), Artificial Immune Systems and their Applications, Springer-Verlag, Berlin, pp. 157-186.

https://en.wikipedia.org/wiki/Clonal_selection (accessed on August 2016).

Ishida, Y. (1990) 'Fully distributed diagnosis by PDP learning algorithm: towards immune network PDP model', Paper Presented at the 1990 IJCNN IEEE International Joint Conference on Neural Networks.

Janeway Jr, C.A., Travers, P., Walport, M. and Shlomchik, M.J. (2001) Immunobiology: the immune system in health and disease, 5th ed., Garland Publishing, New York.

Jang, W.-S., Lee, D.-E. and Choi, J.-h. (2012) 'Ad-hoc performance of wireless sensor network for large scale civil and construction engineering applications', Automation in Construction, Vol. 26, pp. $32-45$.

Jayawardhana, M., Zhu, X., Liyanapathirana, R. and Gunawardana, U. (2017) 'Compressive sensing for efficient health monitoring and effective damage detection of structures', Mechanical Systems and Signal Processing, Vol. 84 (Part A), pp. 414-430.

Jerne, N.K. (1974) 'Towards a network theory of the immune system' Annales d'immunologie, Vol. 125 No. 1-2, pp. 373-389.

Ji, Z. and Dasgupta, D. (2004) 'Augmented negative selection algorithm with variable-coverage detectors' paper presented at the Congress on Evolutionary Computation CEC200. 19-23 June 2004. Portland, OR, US.

Ji, Z. and Dasgupta, D. (2007) 'Revisiting negative selection algorithms', Evolutionary Computation, Vol. 15 No. 2, pp. 223-251.

Jiang, S., Fu, C. and Zhang, C. (2011) 'A hybrid datafusion system using modal data and probabilistic neural network for damage detection', Advances in Engineering Software, Vol. 42 No. 6, pp. 368-374.

Kandel, C.E.R., Schwartz, J.H. and Jessell, T.M. (2000) Principles of neural science, 4th Edition, McGraw-Hill, New York.

Karaboga, D. and Basturk, B. (2007) 'A powerful and efficient algorithm for numerical function optimization: artificial bee colony (ABC) algorithm', J. Glob. Optim. Vol. 39, pp. 459-471.

Kenley, R.M. and Dodds, C.J. (1980) 'West sole WE platform: detection of damage by structural response measurements', $12^{\text {th }}$ annual Offshore Technology Conference vol. 4, pp. 111-118.

Kennedy, J. (2010) 'Particle swarm optimization' in Sammut, C. and Webb, G.I. (Eds) Encyclopedia of machine learning, Springer, New York, NY, US, pp. 760-766.

Kirkegaard, P. and Rytter, A. (1994) 'Use of neural networks for damage assessment in a steel mast' in Proceedings of the 12th International Modal Analysis Conference, Society for Experimental Mechanics, Bethel, CT.

Ko, J.M. and Ni, Y.Q. (2005) 'Technology developments in structural health monitoring of large-scale bridges’, Engineering Structures, Vol. 27 No.12, pp. 1715-1725.

Kudva, J.N., Munir, N. and Tan, P.W. (1991) 'Damage detection in smart structures using neural networks and finite element analysis', Smart Materials and Structures, Vol. 1 No. 2, p. 108.

Langone, R., Reynders, E., Mehrkanoon, S., and Suykens, J.A.K. (2017) 'Automated structural health monitoring based on adaptive kernel spectral clustering', Mechanical Systems and Signal Processing, Vol. 90, pp. 64-78.

Laurentys, C., Ronacher, G., Palhares, R. and Caminhas, W. (2010) 'Design of an Artificial Immune System for fault detection: a negative selection Approach', Expert Systems with Applications, Vol. 37 No.7, pp. 5507-5513.

Lederberg, J. (1959) ‘Genes and antibodies’, Science, Vol. 129 No. 3364, pp. 1649-1653. 
Lei, Y., Kiremidjian, A.S., Nair, K.K., Lynch, J.P. and Law, K.H. (2005) 'Algorithms for time synchronization of wireless structural monitoring sensors', Earthquake Engineering and Structural Dynamics, Vol. 34 No. 6, pp. 555-573.

Leitch, J., Long, A.E., Thompson, A. and Sloan, T.D. (1987) 'Monitoring the behaviour of a major box-girder bridge', in Garston, B.R.E. (Ed), Structural assessment based on full and large-scale testing, Butterworth, Watford, UK, pp. 212-219.

Leng, Q. and Bentwich, Z. (2002) 'Beyond self and nonself: fuzzy recognition of the immune system', Scandinavian journal of immunology, Vol. 56 No. 3, pp. 224-232.

Lentink, D., Jongerius, S.R. and Bradshaw, N.L. (2010) 'The Scalable design of flapping micro-air vehicles inspired by insect flight' in Floreano, D., Zufferey, J.-C., Srinivasan, M.V. and Ellington, C. (Eds), Flying Insects and Robots, Springer, Berlin, pp. 185-205.

Li, P. (2011) 'Structural damage localization using probabilistic neural networks', Mathematical and Computer Modelling, Vol. 54 No. 3, pp. 368-374.

Li, W. (2012) 'PSO based wireless sensor networks coverage optimization on DEMs', in Advanced Intelligent Computing Theories and Applications. With Aspects of Artificial Intelligence, pp. 371-378, Springer, Berlin, Germany.

Li, X. and Yin, M. (2012) 'Application of differential evolution algorithm on self-potential data', PLoS One, Vol. 7 No. 12, e51199.

Lin, T.K., Kiremidjian, A. and Lei, C.Y. (2010) 'A bio-inspired structural health monitoring system based on ambient vibration', Smart Materials and Structures, Vol. 19 No. 11, 115012.

Ling, Q. and Tian, Z. (2010) 'Decentralized sparse signal recovery for compressive sleeping wireless sensor networks', IEEE Transactions on Signal Processing, Vol. 58 No. 7, pp. 3816-3827.

Liu, W. and Chen, B. (2011) 'Optimal control of mobile monitoring agents in immune-inspired wireless monitoring networks', Journal of Network and Computer Applications, Vol. 34 No. 6, pp. 1818-1826.

Liu, P. and Sun, S. (1997) 'The application of artificial neural networks on the health monitoring of bridges' in Chang, F.K. (Ed.), Structural Health Monitoring, Current Status and Perspectives, Technomic publication, Lancaster, pp. 103-110.

Loh, K.J. and Azhari, F. (2012) 'Recent Advances in Skin-Inspired Sensors Enabled by Nanotechnology', J Mater, Vol. 64, No. 7, pp. 793-801.

Loh, K.J., Ryu, D. and Lee, B.M. (2015) 'Bio-inspired Sensors for Structural Health Monitoring', in F. Pacheco Torgal et al. (eds.), Biotechnologies and Biomimetics for Civil Engineering, Springer International Publishing Switzerland, pp. 255-274.

Luh, G.C., Chueh, C.H. and Liu, W.W. (2002) 'MOIA: Multi-objective immune algorithm', Engineering Optimization, Vol. 35 No. 2, pp. 143-164.

Lynch, J.P. (2007) 'An overview of wireless structural health monitoring for civil structures', Philosophical Transactions of the Royal Society, Series A: Mathematical, Physical and Engineering Sciences, Vol. 365 No. 1851, pp. 345-372.

Lynch, J.P., Law, K.H., and Straser, E.G. (2000) 'The development of a wireless modular health monitoring system for civil structures', in Proceedings of the second MCEER workshop on Mitigation of Earthquake Disaster by Advanced Technologies MEDAT-2, pp. 105-108.

Lynch, J.P. and Loh, K.J. (2006) 'A summary review of wireless sensors and sensor networks for structural health monitoring', The Shock and Vibration Digest, Vol. 38 No. 2, pp. 91-128.

McCulloch, W.S. and Pitts, W.H. (1943) 'A logical calculus of the ideas immanent in nervous activity', Bulletin of Mathematical Biophysics, Vol. 5 No. 4, pp. 115-133.

Maeck, J., Peeters, B. and De Roeck, G. (2001) 'Damage identification on the Z24 Bridge using vibration monitoring analysis', Smart Materials and Structures, Vol. 10, No.3, pp. 512-517. 
Magalhães, F., Cunha, A. and Caetano E. (2012) 'Vibration based structural health monitoring of an arch bridge: From automated OMA to damage detection', Mechanical Systems and Signal Processing, Vol. 28, pp. 212-228.

Manning, R. (1994) 'Damage detection in adaptive structures using neural networks' in Proceedings of 35th AIAA/ASME/ASCE/AHS/ASC Structures, Structural Dynamics, and Materials Conference, American Institute of Aeronautics and Astronautics, Washington, DC.

Mascarenas, D., Cattaneo, A., Theiler, J. and Farrar, C. (2013) 'Compressed sensing techniques for detecting damage in structures’, Struct. Health Monit., Vol. 12 No. 4, pp. 325-338.

Masciotta, M.-G., Roque, J.C.A., Ramos, L.F. and Lourenço, P.B. (2016) 'A multidisciplinary approach to assess the health state of heritage structures: The case study of the Church of Monastery of Jerónimos in Lisbon', Construction and Building Materials, Vol. 116, pp. 169-187.

Masciotta, M.-G., Ramos, L.F. and Lourenço, P.B. (2017) 'The importance of structural monitoring as a diagnosis and control tool in the restoration process of heritage structures: a case-study in Portugal', Journal of Cultural Heritage, Vol. 27, pp. 36-47.

Matzinger, P. (2002) 'The danger model: a renewed sense of self', Science, Vol. 296 No. 5566, pp. 301-305.

Mehrjoo, M., Khaji, N., Moharrami, H., Bahreininejad, A. (2008) 'Damage detection of truss bridge joints using artificial neural networks', Expert Systems with Applications, Vol. 35 No. 3, pp. 11221131.

Menon, C. and Setti, M. (2006) 'A biomimetic climbing robot based on the gecko', Journal of Bionic Engineering, Vol. 3 No. 3, pp. 115-125.

Minsky, M. and Seymour, P. (1969) Perceptrons, MIT Press, Cambridge.

Modha, D.S., Ananthanarayanan, R., Esser, S.K., Ndirango, A., Sherbondy, A.J., and Singh, R. (2011) 'Cognitive computing', Communications of the Association for Computing Machinery, Vol. 54 No. 8, pp. 62-71.

Moore, M., Phares, B., Graybeal, B., Rolander, D. and Washer, G. (2001) Reliability of visual inspection for highway bridges, volume I: final report, Report no. FHWA-RD-01-020, Federal Highway Administration, Washington, D.C., USA.

Nakamura, M., Masri, S., Chassiakos, A. and Caughey, T. (1998) 'A method for non-parametric damage detection through the use of neural networks', Earthquake Engineering and Structural Dynamics, Vol. 27 No. 9, pp. 997-1010.

Ni, Y., Zhou, X. and Ko, J. (2006) 'Experimental investigation of seismic damage identification using PCA-compressed frequency response functions and neural network', Journal of Sound and Vibration, Vol. 290 No. 1, pp. 242-263.

O'Connor, S., Lynch, J.P. and Gilbert, A. (2012), 'A modal analysis application of compressed sensing for enhancing energy efficiency in wireless structural monitoring systems', paper presented at the Joint Conference of the Engineering Mechanics Institute and $11^{\text {th }}$ ASCE Joint Specialty Conference on Probabilistic Mechanics and Structural Reliability. 17-20 June 2012.South Bend, IN, USA.

Okundi, E., Aylott, P.J. and Hassenein, A.M. (2003) 'Structural health monitoring of underground railways', in Proceedings of the first international conference on structural health monitoring and intelligent infrastructures SHMII-1, vol. 2, Taylor \& Francis, pp. 1039-1046.

Onur, A. and Osama, A. (2015) 'Self-organizing maps for structural damage detection: a novel unsupervised vibration-based algorithm', Journal of Performance of Constructed Facilities, Vol. 30 No. 3, pp. 04015043.

Peckens, C.A. (2014) Bio-inspired compressive sensing based on auditory neural circuits for real-time monitoring and control of civil structures using resource constrained sensor networks. PhD Thesis, University of Michigan, Ann Arbor, MI, USA. 
Peckens, C. and Lynch, J.P. (2013) 'Utilizing the cochlea as a bio-inspired compressive sensing technique', Smart Materials and Structures, Vol. 22 No. 10, pp. 105027.

Peckens, C. and Lynch, J.P. (2015) 'Resource-efficient wireless sensor network architecture based on bio-mimicry of the mammalian auditory system', Journal of Intelligent Material Systems and Structures, Vol. 26 No. 1, pp. 79-100.

Perelson, A.S. and Oster, G.F. (1979) 'Theoretical studies of clonal selection: minimal antibody', Journal of Theoretical Biology, Vol. 81 No. 4, pp. 645-670.

Perera, R., Sevillano, E., Arteaga, A. and De Diego, A. (2104) 'Identification of intermediate debonding damage in FRP-plated RC beams based on multi-objective particle swarm optimization without updated baseline model', Composites Part B: Engineering, Vol. 62, pp. 205-217.

Povich, C. and Lim, T. (1994) 'An artificial neural network approach to structural damage detection using frequency response functions' in: Proceedings of 35th AIAA/ASME/ASCE/AHS/A SC Structures, Structural Dynamics, and Materials Conference, American Institute of Aeronautics and Astronautics, Washington, DC.

Qian, X., Cao, M., Su, Z. and Chen, J. (2012) 'A Hybrid Particle Swarm Optimization (PSO)-Simplex Algorithm for Damage Identification of Delaminated Beams', Mathematical Problems in Engineering, Vol. 2012, Article ID 607418, 11 pages.

Raghavan, A. and Cesnik, C.E.S. (2007) 'Review of guided-wave structural health monitoring', The Shock and Vibration Digest, Vol. 39 No. 2, pp. 91-116.

Rainieri, C., Fabbrocino, G. and Cosenza, E. (2010) 'Integrated seismic early warning and structural health monitoring of critical civil infrastructures in seismically prone areas', Structural Health Monitoring, Vol. 10 No. 3, pp. 291-308.

Rainieri, C., Fabbrocino, G. and Cosenza, E. (2011) 'Near real-time tracking of dynamic properties for standalone structural health monitoring systems', Mechanical Systems and Signal Processing, Vol. 25 No. 8, pp. 3010-3026.

Ramos, L.F., Marques, L., Lourenço, P.B., De Roeck, G., Campos-Costa, A. and Roque, J. (2010) 'Monitoring historical masonry structures with operational modal analysis: Two case studies', Mechanical Systems and Signal Processing, Vol. 24 No. 5, pp. 1291-1305.

Ramos, L.F., Aguilar, R., Lourenço, P.B. and Moreira, S. (2013) 'Dynamic structural health monitoring of Saint Torcato church', Mechanical Systems and Signal Processing, Vol. 35, No. 1-2, pp. 1-15.

Rosenblatt, F. (1958) 'The perceptron: a probabilistic model for information storage and organization in the brain', Psychological Review, Vol. 65 No. 6, pp. 386-408.

Rumelhart, D.E. and McClelland, J.L. (1986) Parallel distributed processing: explorations in the microstructure of cognition, MIT Press, Cambridge.

Ruochen, L., Haifeng, D. and Licheng, J. (2003), 'Immunity clonal strategies' in Proceedings of Fifth International Conference on Computational Intelligence and Multimedia applications ICCIMA'03.

Rytter, A. and Kirkegaard, P. (1997) 'Vibration based inspection using neural' in Proceedings of the second International Conference on Damage Assessment of Structures DAMAS '97.

Saisi, A., Gentile, C. and Ruccolo, A. (2016) 'Pre-diagnostic prompt investigation and static monitoring of a historic bell-tower', Construction and Building Materials, Vol. 122, pp. 833-844.

Sanders, W., Akhavan, F., Watkins, S. and Chandrashekhara, K. (1997), 'Fiber Optic Vibration Sensing and Neural Networks Methods for Prediction of Composite Beam Delamination' in Proceedings of SPIE - The International Society for Optical Engineering, pp. 858-867.

Severn, R.T., Jeary, A.P. and Ellis, B.R. (1981) 'Forced vibration tests and theoretical studies on dams', E-ISSN 1753-7789, Proceedings of the Institution of Civil Engineers 1981; Vol. 71 No.2, pp. 575-595. 
Shahrivar, F. and Bouwkamp, J.G. (1984) 'Damage detection in offshore platforms using vibration information', in Proceedings of the 3rd Offshore Mechanics and Arctic Engineering Symposium vol. 2, pp. 174-185.

Silva, M., Santos, A., Figueiredo, E., Santos, R., Sales, C., Costa, J.C.W.A. (2016) 'A novel unsupervised approach based on a genetic algorithm for structural damage detection in bridges', Engineering Applications of Artificial Intelligence, Vol. 52, pp. 168-180.

Singh, S. (2003) 'Anomaly detection using negative selection based on the r-contiguous matching rule' in Proceedings of Second International Conference on Artificial Immune System ICARIS 2003, Springer-Verlag, Berlin.

Smith, L.M. (1996) 'In-service monitoring of nuclear-safety-related structures', The Structural Engineer, Vol. 74 No.12, pp. 210-211.

Sohn, H., Farrar, C.R., Hemez, F.M., Shunk, D.D., Stinemates, D.W., Nadler, B.R. and Czarnecki, J.J. (2004) A review of structural health monitoring literature: 1996-2001, Report for the National Laboratory. Report no. LA-13976-MS, Los Alamos.

Spanias, A.S., Jonsson, S.B. and Stearns, S.D. (1991) 'Transform methods for seismic data compression', IEEE Transactions on Geoscience and Remote Sensing, Vol. 29 No. 3, pp. 407-416.

Specht, D.F. (1990) 'Probabilistic neural networks', Neural Network, Vol. 3 No. 1, pp. 109-118.

Spencer, B.F., Ruiz-Sandoval, M. and Kurata, N. (2004) 'Smart sensing technology for structural health monitoring', in Proceedings of $13^{\text {th }}$ World Conference on Earthquake Engineering.

Stephens, J. and Van Luchene, R. (1994) 'Integrated assessment of seismic damage in structures', Computer-Aided Civil and Infrastructure Engineering, Vol. 9 No. 2, pp. 119-128.

Stibor, T., Bayarou, K.M. e Eckert, C. (2004) 'An investigation of r-chunk detector generation on higher alphabets' in Proceeding of the Genetic and Evolutionary Computation Conference GECCO 2004, Springer-Verlag, Berlin, pp. 299-307.

Swartz, R.A., Flatau, A.B., Brooks, C.N., Barkdoll, B.D., Na, S.-M. and Endsley, K.A. (2014) 'Bioinspired magnetostrictive whisker sensors for autonomous bridge scour sensing' in Transportation research board 93rd annual meeting, Washington, DC, pp. 1-12.

Szewczyk, P. and Hajela, P. (1994) 'Damage detection in structures based on feature-sensitive neural networks', ASCE Journal of Computing in Civil Engineering, Vol. 8 No. 2, pp. 163-178.

Tan, G.H. and Chua, K.G. (2003) 'Developing an operational automatic real time tunnel monitoring system', in Proceedings of Underground Singapore 2003, pp. 308-315.

The Biomimicry Institute - Inspiring Sustainable Innovation. [online] http://biomimicry.org (accessed on May 2016).

Timmis, J., Neal, M. e Hunt, J. (2000) ‘An artificial immune system for data analysis’, Biosystems, Vol. 55 No. 1, pp. 143-150.

Ubertini, F., Comanducci, G. and Cavalagli N. (2016) 'Vibration-based structural health monitoring of a historic bell-tower using output-only measurements and multivariate statistical analysis', Structural Health Monitoring, Vol. 15 No. 4, pp. 438 - 457.

Velcro, S.A. (1955) Improvements in or relating to a method and a device for producing a velvet type fabric, Patent no. 721 338, Switzerland.

Verstrynge, E., De Wilder, K., Drougkas, A., Voet, E., Van Balen, K. and Wevers, M. (2018) 'Crack monitoring in historical masonry with distributed strain and acoustic emission sensing techniques', Construction and Building Materials, Vol. 162, pp. 898-907.

Vincent, J.F.V., Bogatyreva, O.A., Bogatyrev, N.R., Bowyer, A. and Pahl, A-K. (2006) 'Biomimetics: its practice and theory', Journal of the Royal Society Interface, Vol. 3 No. 9, pp. 471-482. 
Wang, G.-G. (2016) 'Moth search algorithm: a bio-inspired metaheuristic algorithm for global optimization problems', Memetic Computing, pp. 1-14.

Wang, G.-G., Deb, S., and Cui, Z. (2015a) 'Monarch butterfly optimization', Neural Comput. Appl., DOI 10.1007/s00521-015-1923-y.

Wang, G.-G., Deb, S. and Coelho, L.d.S. (2015b) 'Earthworm optimization algorithm: a bio-inspired metaheuristic algorithm for global optimization problems', Int. J. Bio-Inspir. Comput.

Wang, G.-G., Guo, L., Duan, H. and Wang, H. (2014) 'A new improved firefly algorithm for global numerical optimization', J. Comput. Theor. Nanosci., Vol. 11, pp. 477-485.

Wang, G.-G., Deb, S., Gandomi, A.H., Zhang, Z. and Alavi, A.H. (2016a) 'Chaotic cuckoo search', Soft Comput, Vol. 20, pp. 3349-3362.

Wang, G.-G., Chu, H.E. and Mirjalili, S. (2016b) 'Three-dimensional path planning for UCAV using an improved bat algorithm', Aerospace Science and Technology, Vol. 49, pp. 231-238.

Wang, G.-G., Gandomi, A.H., Alavi, A.H. and Gong, D. (2017) 'A comprehensive review of krill herd algorithm: variants, hybrids and applications’, Artificial Intelligence Review, pp. 1-30.

Watkins, A., Timmis, J. and Boggess, L. (2004) 'Artificial immune recognition system (AIRS): An immune-inspired supervised learning algorithm', Genetic Programming and Evolvable Machines, Vol. 5 No. 3, pp. 291-317.

Widrow, B. and Hoff, M.E. (1960) 'Adaptive switching circuits' in IRE WESCON Convention Record at the Western Electronic Show and Convention.

Wierzchon, S.T. (2002) 'Deriving a concise description of non-self patterns in an artificial immune system', in Jain, L.C. and Kacprzyk, J. (Eds.) New Learning Paradigms in Soft Computing, PhysicaVerlag, Heidelberg, pp. 439-464.

Worden, K. and Cross, E.J. (2018) 'On switching response surface models, with applications to the structural health monitoring of bridges', Mechanical Systems and Signal Processing, Vol. 98, pp. 139156.

Wu, X., Ghaboussi, J. and Garrett, J. (1992) 'Use of neural networks in detection of structural damage', Computers and Structures, Vol.42 No. 4, pp. 649-659.

Xiao, W. (2012) Structural Health Monitoring and fault diagnosis based on artificial immune system. Master Thesis, Worchester Polytechnic Institute, MA, US.

Yen, G. and Kwak, M. (1993) 'Neural network approach for the damage detection of structures', in Proceedings of 34th AIAA/ASME/ASCE/AHS/ASC Structures, Structural Dynamics, and Materials Conference, American Institute of Aeronautics and Astronautics, Washington, United States.

Yi, T.H., Li, H.N. and Gu, M. (2011) 'Optimal Sensor Placement for Health Monitoring of High-Rise Structure Based on Genetic Algorithm', Mathematical Problems in Engineering, Vol. 2011, Article ID 395101, 12 pages.

Yi, T.H., Li, H.N. and Zhang, X.D. (2012) 'A modified monkey algorithm for optimal sensor placement in structural health monitoring', Smart Mater. Struct., Vol. 21, 105033.

Yi, T.H., Li, H.N. and Zhang, X.D. (2015) 'Health monitoring sensor placement optimization for Canton Tower using immune monkey algorithm', Structural Control and Health Monitoring, Vol. 22 No. 1, pp. 123-138.

Yost, W.A. (1994) Fundamentals of hearing: an introduction, Academic Press, New York.

Yu, L. and Xu, P. (2011) 'Structural health monitoring based on continuous ACO method', Microelectronics Reliability, Vol. 51 No. 2, pp. 270-278.

Yu, Y. and Hou, C. (2004) 'A clonal selection algorithm by using learning operator' in Proceedings of the Third International Conference on Machine Learning and Cybernetics. 
Yu, L., Santoni-Bottai, G., Xu, B., Liu, W. and Giurgiutiu, V (2008) 'Piezoelectric wafer active sensors for in situ ultrasonic-guided wave SHM', Fatigue Fract Eng Mater Struct, Vol. 31, pp. 611-628.

Zhang, Y. and Li, J. (2006) 'Wavelet-based vibration sensor data compression technique for civil infrastructure condition monitoring', Journal of Computing in Civil Engineering, Vol. 20 No. 6, pp. 390-399.

Zhang, J., Worden, K. and Staszewski, W.J. (2008), 'Sensor optimization using an immune system metaphor' in Proceedings of 26th International Modal Analysis Conference IMAC 2008.

Zhang, Z., Zhang, N. and Feng, Z. (2014) 'Multi-satellite control resource scheduling based on ant colony optimization', Expert Syst Appl, Vol. 41 No. 6, pp. 2816-2823.

Zhao, F. and Guibas, L. (2004) Wireless sensor networks: an information processing approach, Morgan Kaufman, San Francisco, CA, US.

Zheng, S.J., Li, Z.Q. and Wang, H.T. (2011) 'A genetic fuzzy radial basis function neural network for structural health monitoring of composite laminated beams', Expert Systems with Applications, Vol. 38 No. 9, pp. 11837-11842.

Zheng, Y., Bai, H., Huang, Z., Tian, X., Nie, F.-Q., Zhao, Y., Zhai, J. and Jiang, L. (2010) 'Directional water collection on wetted spider silk', Nature, Vol. 463 No. 7281, pp. 640-643.

Zhu, D., Yi, X., Wang, Y., Lee, K.-M. and Guo, J. (2010) 'A mobile sensing system for structural health monitoring: design and validation', Smart Mater Struct, 19:055011/1-11. 


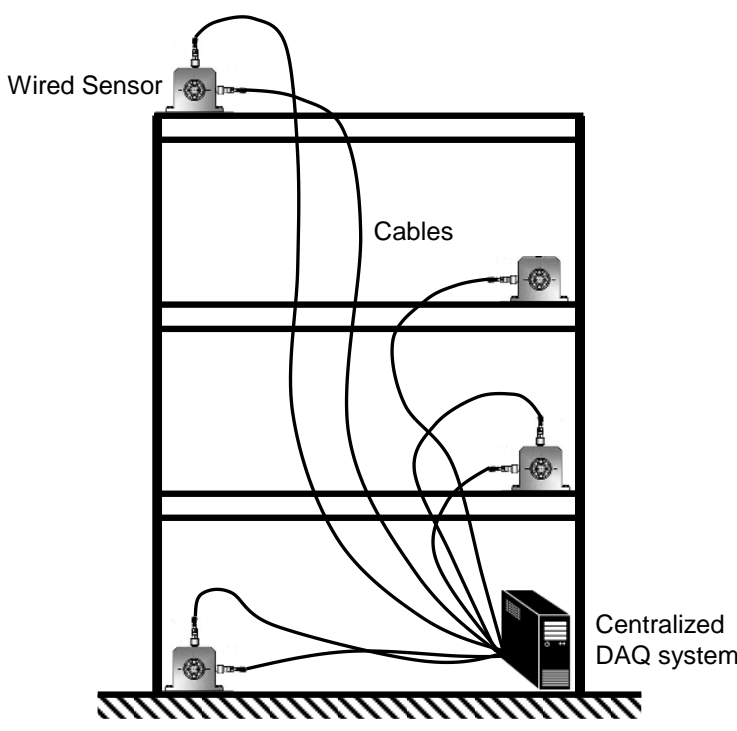

(a)

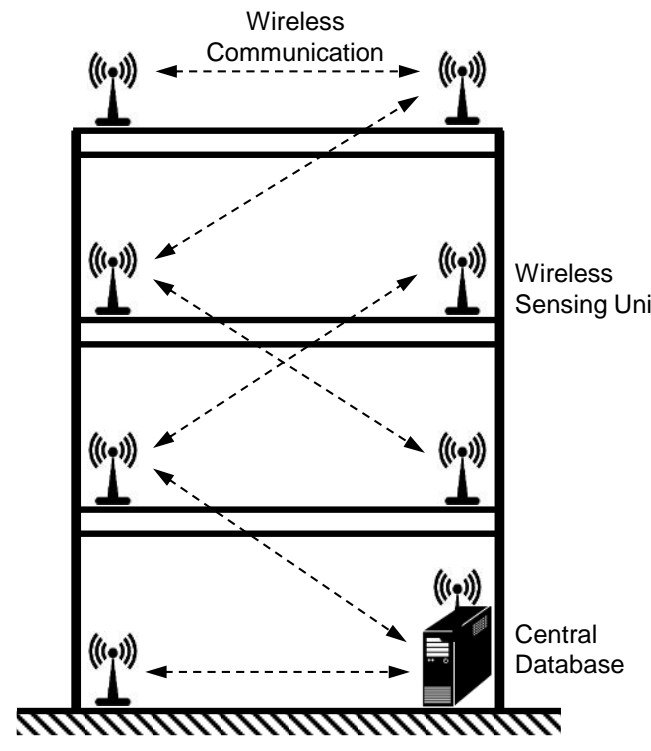

(b)

Figure 1 -Configuration of structural monitoring systems: tethered (a) versus (b) wireless. 


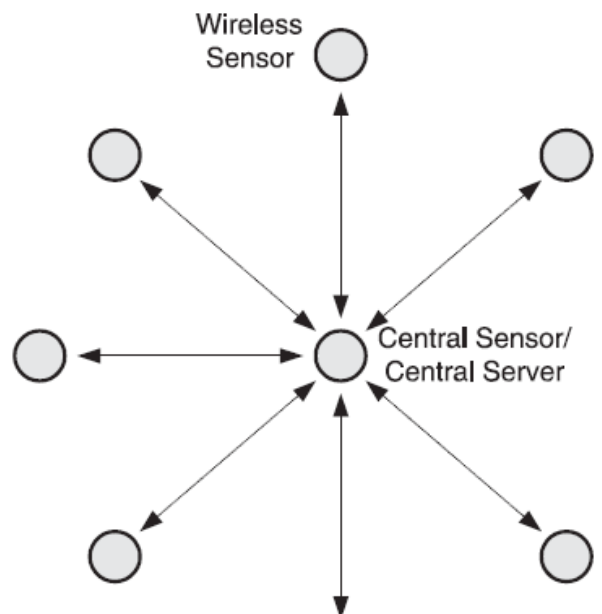

(a)

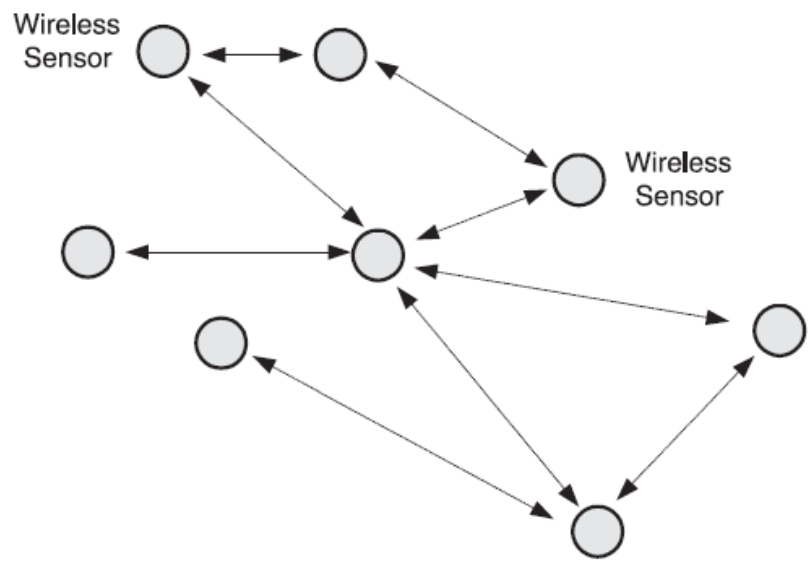

(b)

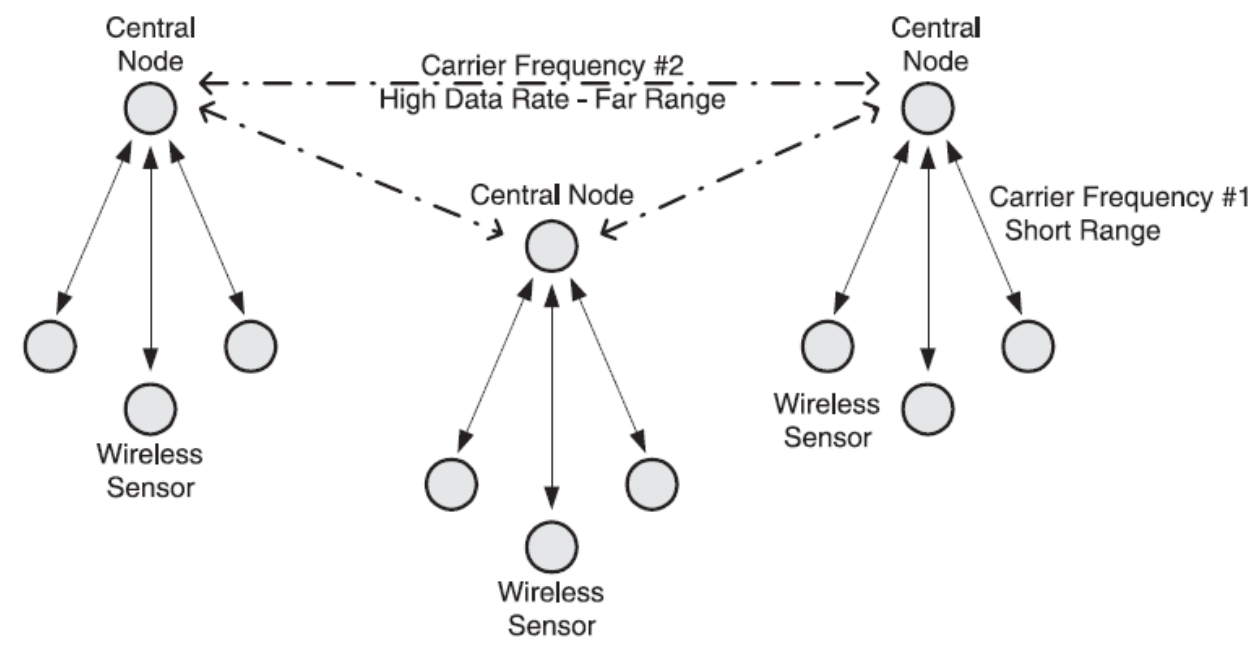

(c)

Figure 2 - Wireless network topologies for wireless sensor networks: (a) star; (b) peer-to-peer; (c) two-tier network topologies (Lynch and Loh, 2006). 


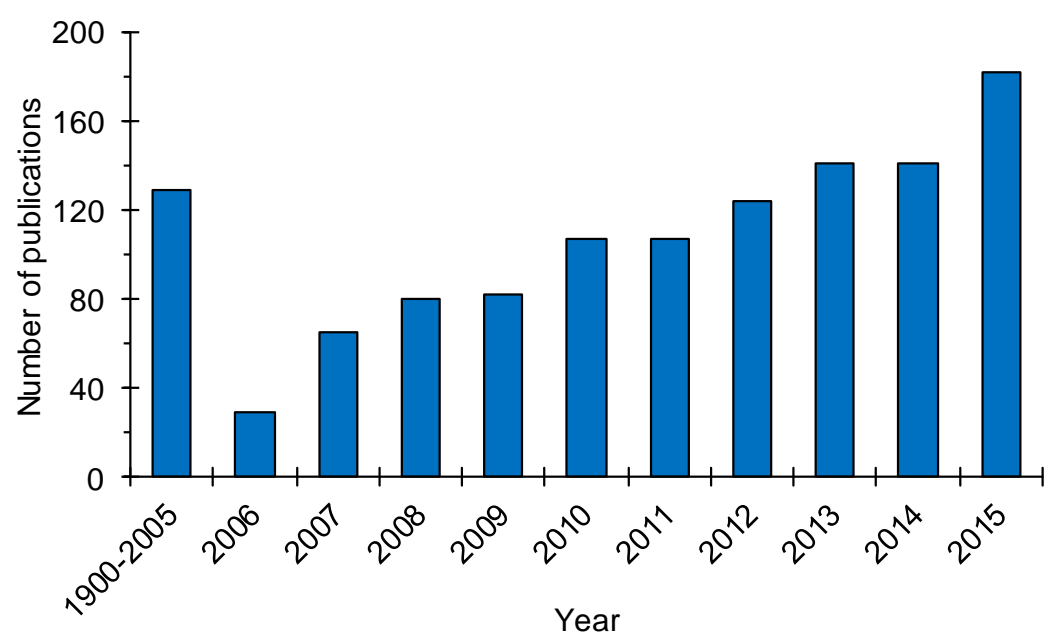

Figure 3 - Number of publications containing the words biomimetics and biomimicry associated with engineering in the title, abstract, or keywords. The data is obtained from searching the ISI Web of Science database (SCI-EXPANDED, The Thompson Corporation, 2016) using the terms biomimetic or biomimicry engineering in the topic field. 


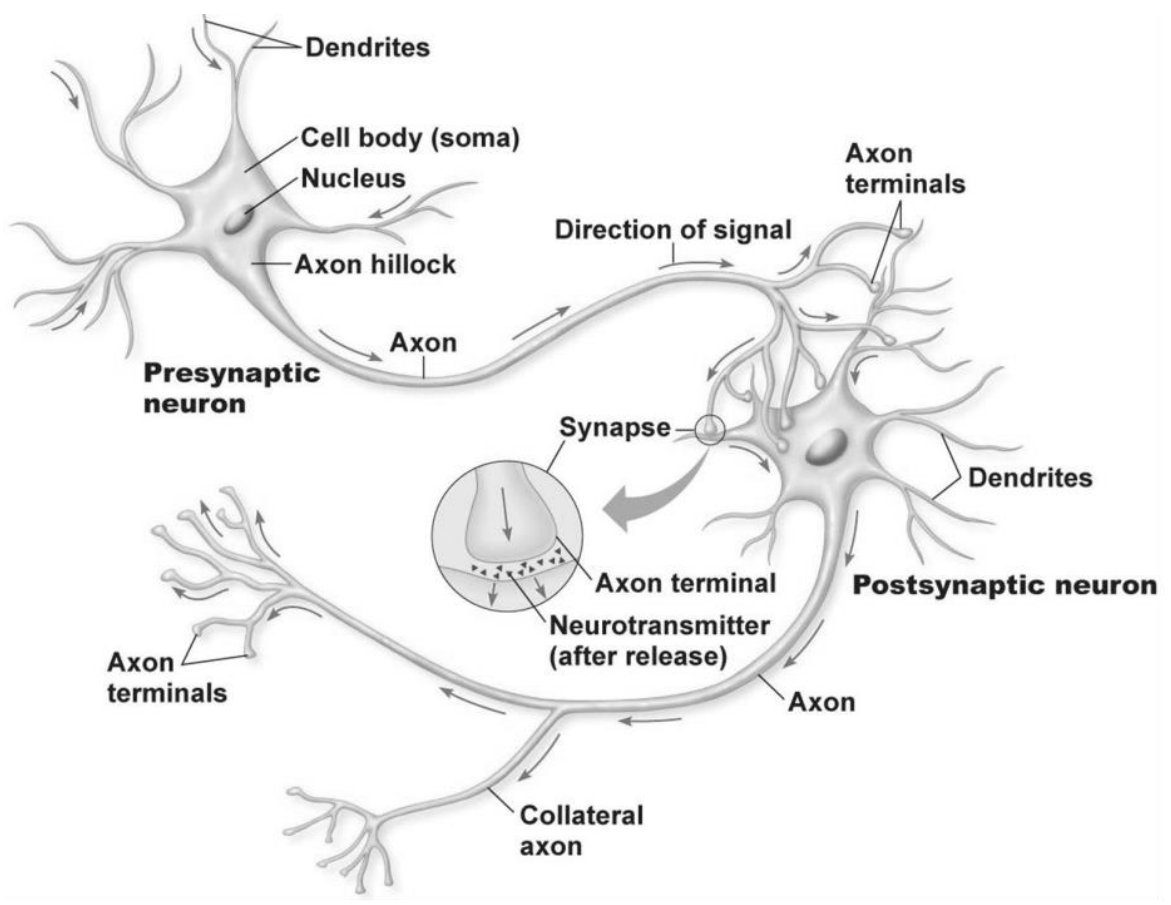

Figure 4 - Schematic architecture of two neurons (droualb.faculty.mjc.edu). 


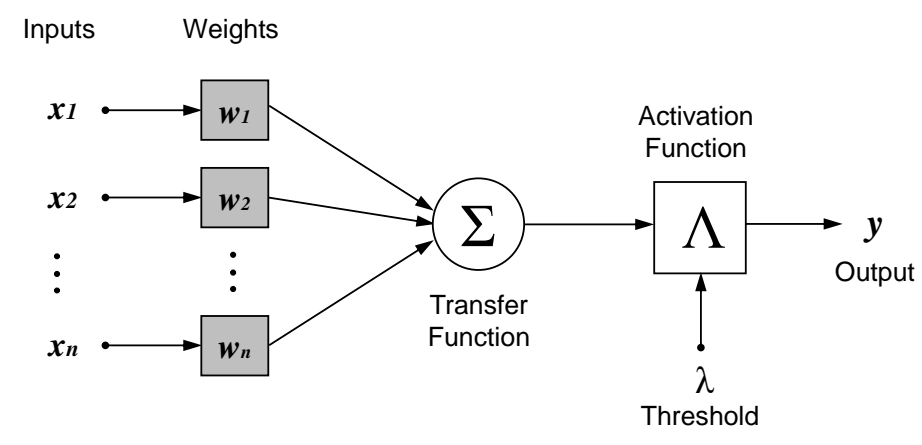

Figure 5 - Model of McCulloch-Pitts perceptron. 


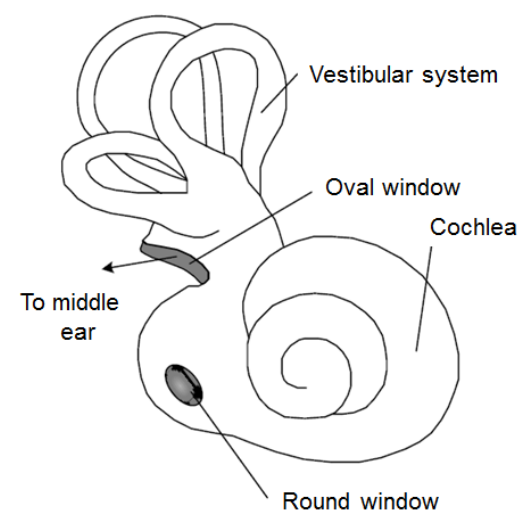

(a)

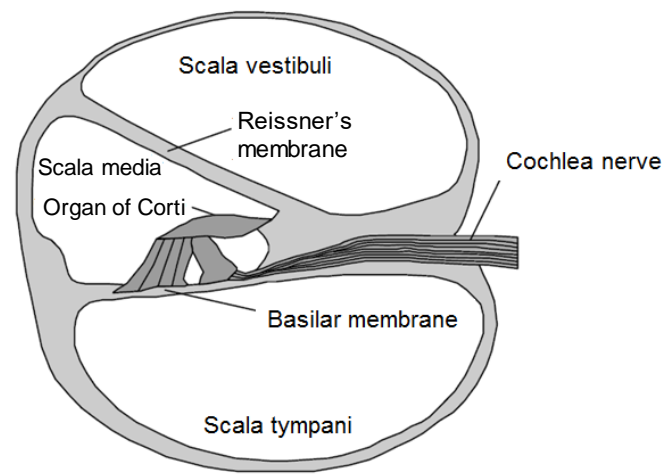

(b)

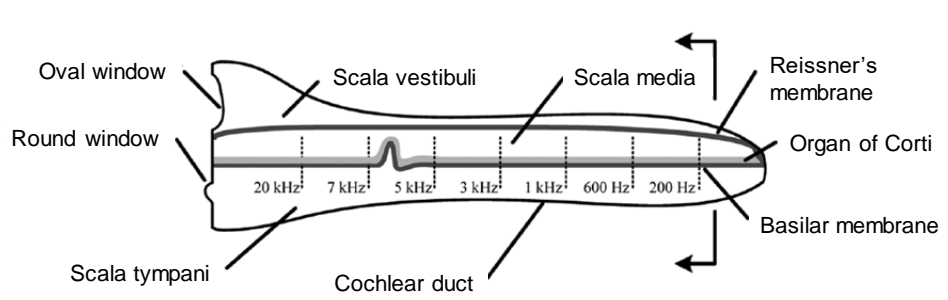

(c)

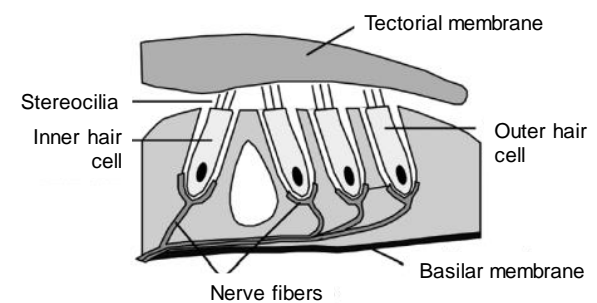

(d)

Figure 6 - Schematic representation of the mammalian cochlea system: (a) inner ear; (b) cross-section of the cochlea; (c) uncoiled cochlea indicating the vibrating subsections of the basilar membrane; and (d) cross-section of basilar membrane and organ of Corti (Peckens and Lynch, 2015). 


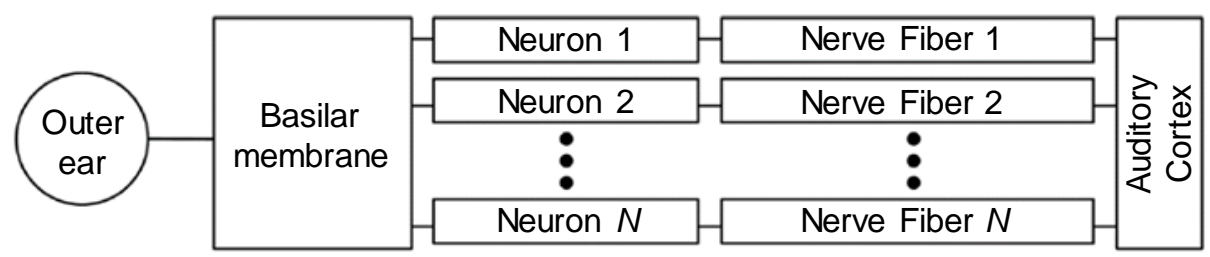

(a)

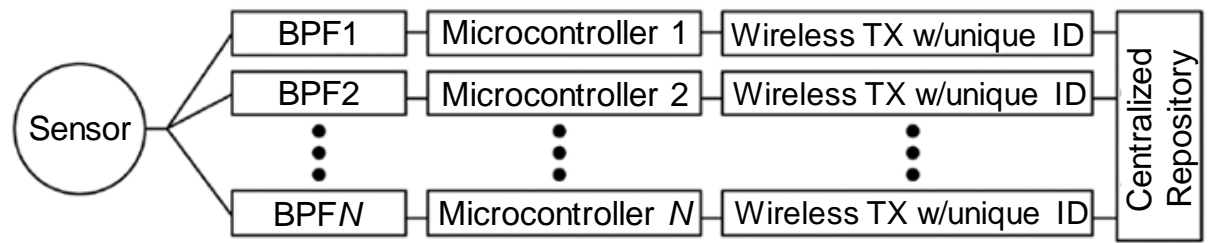

(b)

Figure 7 - Simplified representation of (a) the mammalian auditory process in comparison with the process of (b) the cochlea-inspired sensing system (adapted from Peckens and Lynch, 2015). 


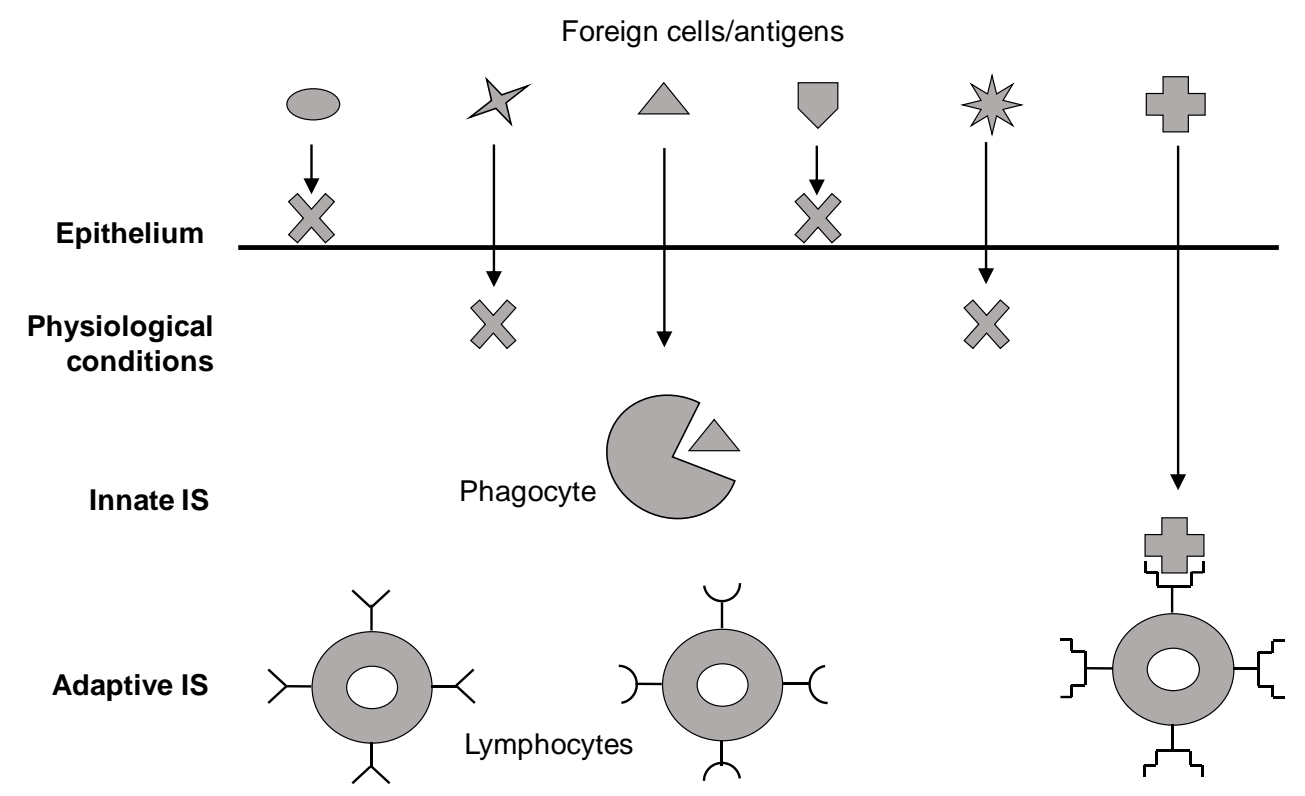

Figure 8 - Schematic representation of the multilevel defence structure of the immune system (adapted from Anaya et al., 2015). 


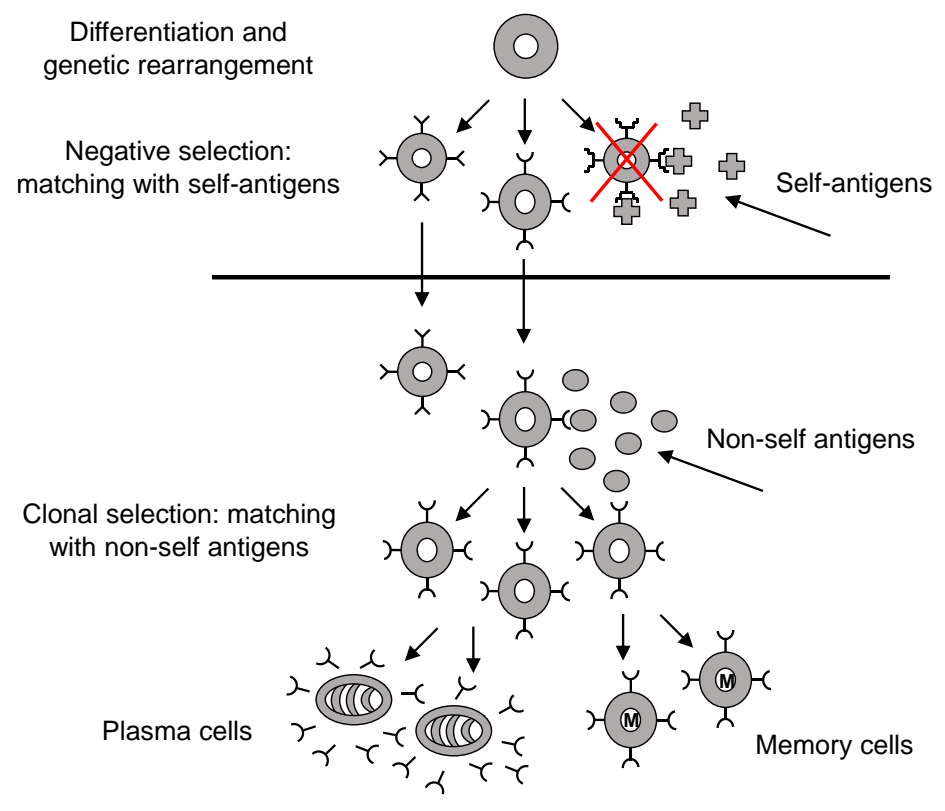

Figure 9 - Simplified representation of negative and clonal selection theories. In negative selection, lymphocytes that bind to antigens from the body's own tissues are destroyed, while the rest mature into inactive lymphocytes. In clonal selection, the lymphocytes that encounter a match with foreign antigens are cloned (adapted from https://en.wikipedia.org/wiki/Clonal_selection). 


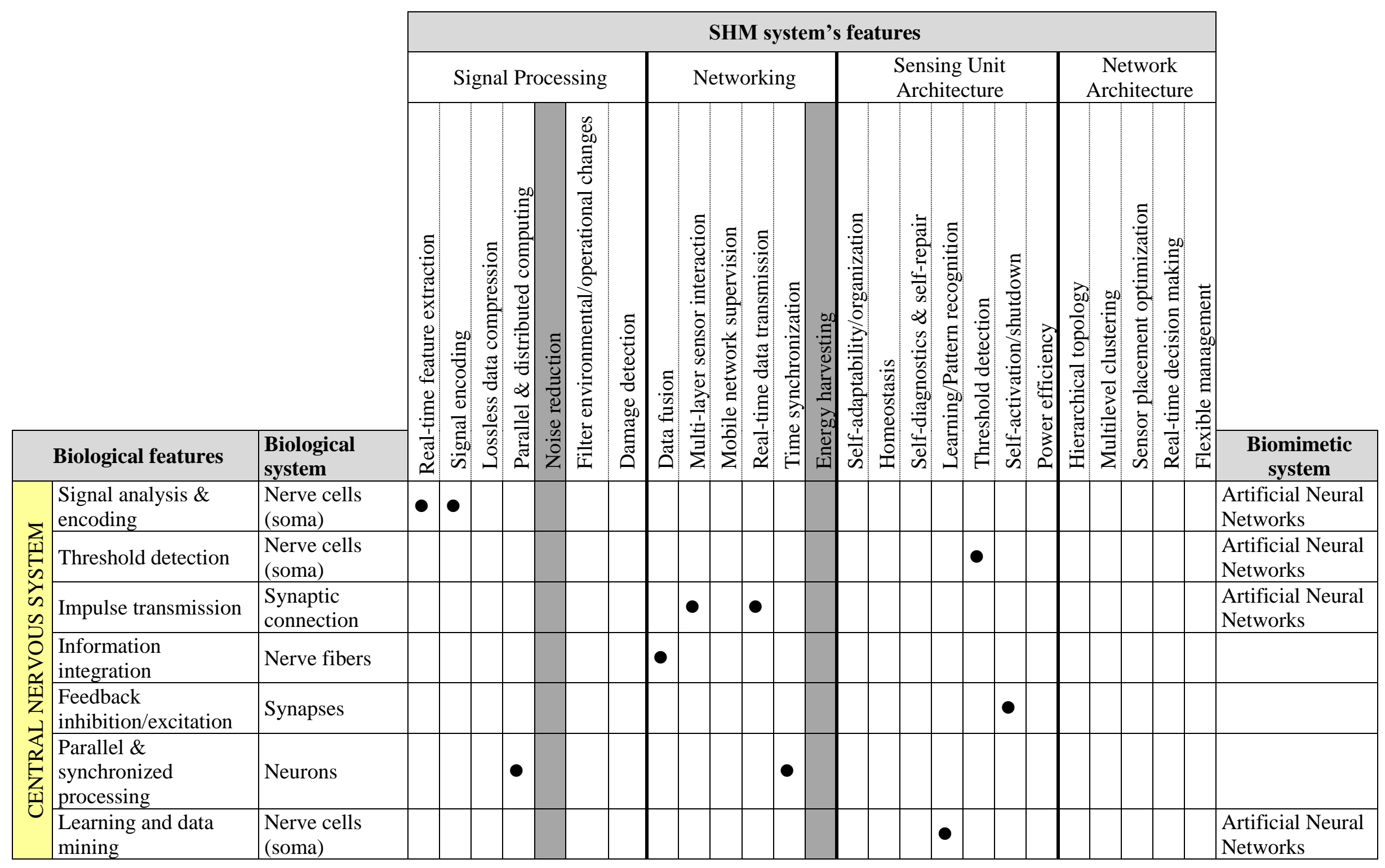




\begin{tabular}{|c|c|c|c|c|c|c|c|c|c|c|c|c|c|c|c|c|c|c|c|c|c|c|c|c|}
\hline & $\begin{array}{l}\text { Metabolic expense } \\
\text { reduction }\end{array}$ & $\begin{array}{l}\text { Axons' myelin } \\
\text { sheath }\end{array}$ & & & & & & & & & & & & & & & & $\bullet$ & & & & & & \\
\hline & $\begin{array}{l}\text { Self-support and } \\
\text { nutrition }\end{array}$ & Glial cells & & & & & & & & & & & & & & & & $\bullet$ & & & & & & \\
\hline & $\begin{array}{l}\text { Adaptability to input } \\
\text { stimuli }\end{array}$ & $\begin{array}{l}\text { Synaptic } \\
\text { connection }\end{array}$ & & & & & & & & & & & $\bullet$ & & & & & & & & & & & \\
\hline & Optimal coverage & \begin{tabular}{|l} 
Neurons' \\
number
\end{tabular} & & & & & & & & & & & & & & & & & & & $\bullet$ & & & \\
\hline & Multilevel physiology & Neural clusters & & & & & & & & 0 & & & & & & & & & & $\bullet$ & & & $\bullet$ & $\begin{array}{l}\text { Artificial Neural } \\
\text { Networks }\end{array}$ \\
\hline & $\begin{array}{l}\text { Real-time decision } \\
\text { making }\end{array}$ & Brain & & & & & & & & & & & & & & & & & & & & 0 & & \\
\hline & $\begin{array}{l}\text { Hierarchical } \\
\text { Morphology }\end{array}$ & Nervous system & & & & & & & & & & & & & & & & & 0 & & & & & \\
\hline$\sum_{i=1}$ & \begin{tabular}{|l|} 
Spectral \\
decomposition
\end{tabular} & \begin{tabular}{|l} 
Basilar \\
membrane
\end{tabular} & 0 & & & & & & & & & & & & & & & & & & & & & $\begin{array}{l}\text { Bandpass filter } \\
\text { bank }\end{array}$ \\
\hline$\sqrt{2}$ & Peak values encoding & Organ of Corti & & 0 & & & & & & & & & & & & & & & & & & & & Microcontrollers \\
\hline 덥 & Data compression & Inner hair cells & & & 0 & & & & & & & & & & & & & & & & & & & w/ peak-picking \\
\hline ठ & Data transmission & $\begin{array}{l}\text { Hair-cell } \\
\text { neurons }\end{array}$ & & & & & & & & & & $\bullet$ & & & & & & & & & & & & linear encoding \\
\hline & $\begin{array}{l}\text { Multilevel defence } \\
\text { organisation }\end{array}$ & $\begin{array}{l}\text { Skin-Inn.IS- } \\
\text { Adap.IS }\end{array}$ & & & & & $\bullet$ & & & & & & $\bullet$ & & & & & & & $\bullet$ & & $\bullet$ & $\bullet$ & \\
\hline$\sum_{\square=1}$ & Alarm issue & $\begin{array}{l}\text { Innate immune } \\
\text { system }\end{array}$ & & & & & & $\bullet$ & & & & & & & & & $\bullet$ & & & & & & & \\
\hline 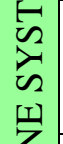 & Pattern recognition & Lymphocytes & & & & & & $\bullet$ & & & & & & & & • & & & & & & & & $\begin{array}{l}\text { Pattern } \\
\text { recognition } \\
\text { algorithms } \\
\end{array}$ \\
\hline 岁 & Cells communication & Cell receptors & & & & & & & & 0 & & & & & & & & & & & & & & \\
\hline$\sum$ & Cells clonation & B lymphocytes & & & & & & & 0 & & & & & & $\bullet$ & & & & & & & & & $\begin{array}{l}\text { Clonal selection } \\
\text { algorithms }\end{array}$ \\
\hline & Cells patrolling & B-cells & & & & & & & & & 0 & & & & & & & & & & & & & $\begin{array}{l}\text { Software- } \\
\text { embedded agents }\end{array}$ \\
\hline
\end{tabular}




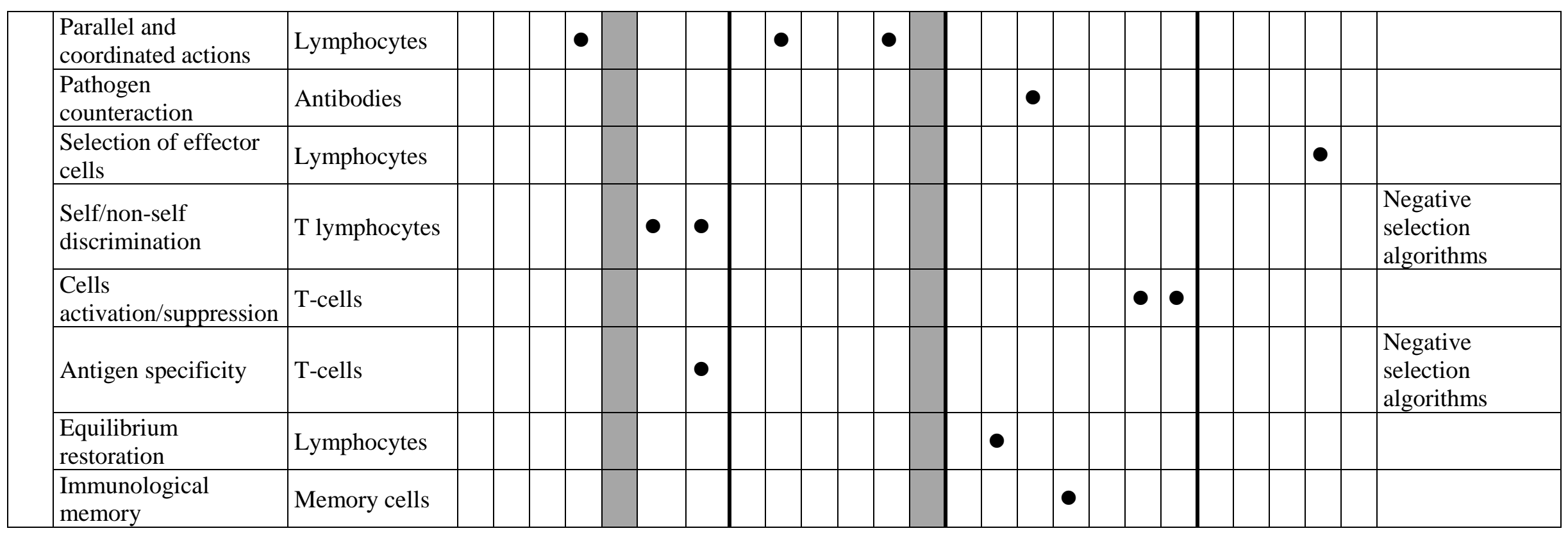

Table 1. Compatibility-matrix of functional analogies between biological and SHM systems (cells with dots indicate matching features). 